\title{
Al-driven peculiarities of local coordination and magnetic properties in single-phase $\mathrm{Al}_{X}-\mathrm{CrFeCoNi}$ high-entropy alloys
}

\author{
${ }^{1}$ Helmholtz-Zentrum Berlin für Materialien und Energie (HZB), D-12489, Germany \\ ${ }^{2}$ Institute of Solid State Physics, University of Latvia, LV-1063, Latvia \\ ${ }^{3}$ Bundesanstalt für Materialforschung und - prüfung (BAM), D-12489, Germany
}

Alevtina Smekhova ${ }^{1}(\triangle), \quad$ Alexei Kuzmin ${ }^{2}, \quad$ Konrad Siemensmeyer ${ }^{1}, \quad$ Chen Luo ${ }^{1}$, Kai Chen ${ }^{1}, \quad$ Florin Radu ${ }^{1}$ Eugen Weschke ${ }^{1}$, Uwe Reinholz ${ }^{3}$, Ana Guilherme Buzanich ${ }^{3}$, and Kirill V. Yusenko ${ }^{3}(\triangle)$

(C) The Author(s) 2021

Received: 7 March 2021 / Revised: 14 June 2021 / Accepted: 21 June 2021

\begin{abstract}
Modern design of superior multi-functional alloys composed of several principal components requires in-depth studies of their local structure for developing desired macroscopic properties. Herein, peculiarities of atomic arrangements on the local scale and electronic states of constituent elements in the single-phase face-centered cubic (fcc)- and body-centered cubic (bcc)-structured high-entropy $\mathrm{Al}_{x}-\mathrm{CrFeCoNi}$ alloys ( $x=0.3$ and 3 , respectively) are explored by element-specific $\mathrm{X}$-ray absorption spectroscopy in hard and soft X-ray energy ranges. Simulations based on the reverse Monte Carlo approach allow to perform a simultaneous fit of extended $\mathrm{X}$-ray absorption fine structure spectra recorded at $\mathrm{K}$ absorption edges of each $3 \mathrm{~d}$ constituent and to reconstruct the local environment within the first coordination shells of absorbers with high precision. The revealed unimodal and bimodal distributions of all five elements are in agreement with structure-dependent magnetic properties of studied alloys probed by magnetometry. A degree of surface atoms oxidation uncovered by soft X-rays suggests different kinetics of oxide formation for each type of constituents and has to be taken into account. X-ray magnetic circular dichroism technique employed at $L_{2,3}$ absorption edges of transition metals demonstrates reduced magnetic moments of $3 \mathrm{~d}$ metal constituents in the sub-surface region of in situ cleaned fcc-structured $\mathrm{Al}_{0.3}-\mathrm{CrFeCoNi}$ compared to their bulk values. Extended to nanostructured versions of multicomponent alloys, such studies would bring new insights related to effects of high entropy mixing on low dimensions.
\end{abstract}

\section{KEYWORDS}

high-entropy alloys, reverse Monte Carlo, magnetism, element-specific spectroscopy, extended X-ray absorption fine structure (EXAFS), X-ray magnetic circular dichroism (XMCD)

\section{Introduction}

High-entropy alloys (HEAs) present a broad class of multicomponent materials with a high variety of their composition and microstructure peculiarities. Exploration of entropy stabilization concept and its influence on materials properties began in the early XXI ${ }^{\text {st }}$ century $[1,2]$ and attracts more and more attention from the materials science community $[3,4]$. In early works, HEAs have been reported to crystallize as singlephase alloys with randomly distributed atoms among the phase [5]. Nevertheless, more detailed studies suggested the existence of atomic aggregation and long-range order [6-8]. It has been also postulated that atomic aggregation, as well as formation and dissolution of intermetallic secondary phases, may play a key role in HEA's structural and chemical stability and their physical properties.

In general, HEAs exhibit high mechanical and chemical stability under high-temperature and high mechanical impact [9], low magnetic anisotropy, reasonably large saturation magnetisation, and high Curie temperature [10] together with the absence of ductile to brittle transition and high strength [11]. A number of HEAs was proposed to be single-phase (mainly body-centered cubic (bcc) or face-centered cubic (fcc)) alloys with minor inclusions of other ordered phases due to high mixing entropy $[12,13]$. Nevertheless, depending on the composition, they reveal a quite complex nature of lattice distortions and magnetic behaviour resulting in a strong dependence of the spontaneous magnetization and the long-range ferromagnetic order on the aggregation of their components [14]. Due to a spin-driven nature of a particular metal ordering in HEAs [15], clustering and dislocations can be considered as a way to reduce the magnetic frustration of the magnetic interactions between nearestneighbours as it was shown for high-entropy oxides $[16,17]$. Despite intensive macroscopic studies of HEAs using highresolution imaging and X-ray diffraction, key questions are still not clarified since local coordination/clustering on the atomic scale and especially magnetic ordering, absolute values of the magnetic moments, and the presence of magnetic phase transitions at high magnetic fields in homogeneous single-phase alloys were barely investigated using element-specific techniques up to now.

$\mathrm{Al}_{x}-\mathrm{CrFeCoNi} \mathrm{HEAs}$ are considered as suitable model alloys for studies of interdependences of structure and different macroscopic and microscopic properties in compositionally complex systems that form a chemically random solid solution. It is well known 
that light and relatively large $\mathrm{Al}$ atoms act as bcc-stabilizer and, hence, the crystallographic structure of $\mathrm{Al}_{x}-\mathrm{CrFeCoNi}$ can be easily tuned by the changing of $\mathrm{Al}$ content [18]. For $x<0.3$, a single-phase fcc-structured alloy was detected whereas for $x>0.3$ a pure bcc structure has been proposed $[19,20]$. That, in turn, influences drastically its mechanical, resistivity, ductile, and magnetic properties $[21,22]$. At the same time, $\mathrm{Al}_{x}-\mathrm{CrFeCoNi}$ HEAs show phase instability upon heating and compression and undergo phase separation only above $900 \mathrm{~K}$ [23-25]. For our studies, we chose fcc-structured $\mathrm{Al}_{0.3}-\mathrm{CrFeCoNi}$ and bccstructured $\mathrm{Al}_{3}-\mathrm{CrFeCoNi}$ HEA systems prepared by induction melting in an Ar filled glove-box from powders of pure metals as described in previous works [23-25]. Hereafter, these systems will be denoted as fcc- and bcc-HEA, respectively.

Local ordering and distortions related to the presence of specific atomic species with different atomic radii were investigated in recent works predominantly by X-ray and neutron diffraction which cannot distinguish individual element contributions. Several attempts to use extended X-ray absorption fine structure (EXAFS) which is naturally an element-specific technique can be considered as a primary tool to probe local structure, interatomic distances, and their expected deviations due to non-equivalent nearest-neighbours in complex alloys encountered some difficulties. Applying a non-conventional approach to the data analysis makes it possible to study HEAs comprised of five different principal elements, e.g., Pd-NiCoFeCr, $\mathrm{Mn}-\mathrm{NiCoFeCr}$, and $\mathrm{Mg}-\mathrm{Al}-\mathrm{FeCuCr}$ alloys, within several approximations [26-29]. In the current manuscript, to get a maximal benefit from EXAFS spectroscopy, we employ another approach-atomistic simulations based on the reverse Monte Carlo (RMC) method-which provides the possibility to fit wavelet transforms (WTs) of experimental EXAFS spectra taken at several $\mathrm{K}$ absorption edges and to determine pair distribution functions associated with local configurations of each constituent element in the five-component HEAs. These outcomes are unattainable for other techniques such as diffraction or atom probe tomography.

To probe the surface oxidation that may significantly influence corrosion, catalytic, electrochemistry, and magnetic properties of HEAs, X-ray absorption near edge structure (XANES) probed by soft X-rays at the $\mathrm{L}_{2,3}$ absorption edges of $3 \mathrm{~d}$ metals was used. A signature of non-equivalent development of constituent degradation on HEA surfaces under water and air conditions was found. Besides, an impact of hybridization effects between $\mathrm{Al}$ and $3 \mathrm{~d}$ electrons of transition metal elements was observed at the $\mathrm{K}$ absorption edge of aluminum.

As a step towards understanding magnetic properties of HEAs which are strongly dependent on symmetry, composition, and local distortions $[14,21,30]$, an element-specific technique like Xray magnetic circular dichroism (XMCD) can be employed in addition to conventional magnetometry. It reveals the absolute value of magnetic moments separately for each $3 \mathrm{~d}$ component. Herein, we apply XMCD technique to probe magnetic moments of $3 \mathrm{~d}$ atoms located in the sub-surface volume of the fcc-HEA. Considering together the structural findings, electronic properties, and magnetic results revealed by element-specific spectroscopy with hard and soft X-rays, it becomes possible to gain new insights of $\mathrm{Al}_{x}-\mathrm{CrFeCoNi}$ high-entropy alloys on the local scale.

\section{Experimental}

\subsection{Sample preparation and prior characterization}

As-cast fcc-structured $\mathrm{Al}_{0.3}-\mathrm{CrFeCoNi}$ (denoted as fcc-HEA) and bcc-structured $\mathrm{Al}_{3}-\mathrm{CrFeCoNi}$ (denoted as bcc-HEA) samples (the empirical formulas are given according to energy dispersive X-ray
(EDX) analysis of the alloys) were prepared by induction melting in an Ar filled glove-box from powders of pure metals that were loaded in hexagonal boron nitride crucibles. The weight of each sample was typically ca. $5 \mathrm{~g}\left(\mathrm{ca} .1 \mathrm{~cm}^{3}\right)$. Complete melting of the samples was achieved above 1,900 K. After 1-2 min at the melting temperature, the samples were cooled down naturally to room temperature (RT); the cooling process lasted no longer than a minute. To ensure homogeneity three equivalent cycles of remelting were used; so, it can be assumed that the element distribution of the samples prepared in such a way represents an equilibrium state of the alloy near the melting temperature [31]. Then, the bcc-HEA sample was powdered using a Fritsch Planetary Mill PULVERISETTE 5/2 (36 h, $250 \mathrm{rpm}$ ). fcc-HEA sample was studied in the form of polished disks. More details about sample preparation, alloy microstructure, differential scanning calorimetry results (up to $1,300 \mathrm{~K}$ ), and mechanical properties can be found in Yusenko et al. [23] .

Initial structural characterisation of studied HEAs was done by synchrotron-based X-ray diffraction (SR-XRD) under hydrostatic compression in diamond anvil cells. Powder SR-XRD data were collected at room temperature at the P.02.2. beam-line, PETRA III, DESY in Hamburg $(\lambda=0.29036 \AA$, Perkin Elmer XRD1621 $(2,048 \times 2,048$ pixels, $200 \mu \mathrm{m} \times 200 \mu \mathrm{m})$ flat panel detector, beam size $3 \mu \mathrm{m}(v) \times 3 \mu \mathrm{m}(h))$, and have shown phase stability under compression at room temperature up to $60 \mathrm{GPa}$ [23]. An absence of phase separation is clear proof for a truly single-phase nature of both alloys. An example of diffraction patterns collected for the samples studied at ambient conditions could be found in Fig. S1 in the Electronic Supplementary Material (ESM).

The sample with a small nominal Al-content of $x \sim 0.3$ revealed a stable fcc structure in agreement with the results of previous works. The unit cell parameter and atomic volume of the fcc-HEA were determined to be $a_{\mathrm{fcc}}=3.572(2) \AA$ and $V / Z_{\mathrm{fcc}}=11.39(2)$ $\AA^{3} \cdot$ atom $^{-1}$, respectively. By increasing $x$ up to 3 , an expected structural transformation to a bcc phase was realized. B2-type longrange ordering of the bcc-HEA sample was confirmed by a presence of (100) super-lattice peak in the SR-XRD patterns as previously reported for Al-rich HEAs sub-lattice [32-35]. As soon as a partially ordered bcc unit cell and a partially disordered B2 crystal structure are identical, herein we used the bcc-notation for the $\mathrm{Al}$-rich $\mathrm{Al}_{3}-\mathrm{CrFeCoNi}$ alloy. The unit cell parameter became smaller as $a_{\mathrm{bcc}}=2.877(2) \AA$ while the atomic volume of $V / Z_{\mathrm{bcc}}=$ 11.97(3) $\AA^{3} \cdot$ atom $^{-1}$ was found to be enlarged compared to the fccHEA sample. The powder grains of $\sim 100 \mu \mathrm{m}$ predominant size were found to be free from any non-equiaxed dendrites.

The precise elemental composition of as-cast fcc- and bccHEAs was determined using a Hitachi S-4800 field emission scanning-electron microscope (SEM) equipped with an EDX analyser and is presented in Table 1 . The average elemental composition was obtained from $2.5 \mathrm{~mm} \times 1.5 \mathrm{~mm}$ maps. It was also found that all elements are homogeneously distributed within alloys on the $\mu \mathrm{m}$-scale.

\subsection{EXAFS at $\mathrm{K}$ edges of $3 \mathrm{~d}$ constituents}

EXAFS spectra were recorded in transmission at the $\mathrm{Fe}(7.11$ $\mathrm{keV})$, Co (7.71 keV), Ni (8.33 keV), and $\mathrm{Cr}(5.99 \mathrm{keV}) \mathrm{K}$ absorption edges at BAMline at the Helmholtz-Zentrum Berlin (HZB, BESSY II, Berlin, Germany) [36] with horizontally polarized hard X-rays from a $7 \mathrm{~T}$ shifter at room temperature in air. fcc- and bcc-HEA samples in powder form were mixed with hexagonal boron nitride and pressed between two $50 \mu \mathrm{m}$ Kapton foils. The signal from the upstream ionization chamber filled with air/argon mixture (ca. 1:1 (v/v)) was used for the normalization of the X-ray incoming intensity. 
Table 1 Structural parameters of as-cast fcc- and bcc-HEAs determined from SR-XRD data and atomic compositions taken from EDX analysis

\begin{tabular}{|c|c|c|}
\hline & fcc- $\mathrm{Al}_{0.3} \mathrm{CrFeCoNi}$ as-cast ca. $1,900 \mathrm{~K}$ & bcc- $\mathrm{Al}_{3} \mathrm{CrFeCoNi}$ as-cast ca. $1,973 \mathrm{~K}$ \\
\hline \multicolumn{3}{|c|}{ Structural parameters at ambient conditions } \\
\hline Unit cell parameter, $a(\AA)$ & $3.572(2)$ & $2.877(2)$ \\
\hline \multirow[t]{2}{*}{ Atomic volume, $V / Z\left(\AA^{3} \cdot\right.$ atom $\left.^{-1}\right)$} & $11.39(2)(Z=4)$ & $11.97(3)(Z=2)$ \\
\hline & \multicolumn{2}{|c|}{ Sample composition (at.\%) } \\
\hline $\mathrm{Al}$ & $7.9(2)$ & $44.4(3)$ \\
\hline $\mathrm{Cr}$ & $23.4(2)$ & $13.6(2)$ \\
\hline $\mathrm{Fe}$ & $23.3(2)$ & $14.3(4)$ \\
\hline Co & $22.2(2)$ & $14.7(2)$ \\
\hline $\mathrm{Ni}$ & $23.2(2)$ & $12.8(9)$ \\
\hline
\end{tabular}

\subsection{Reverse Monte Carlo analysis of EXAFS}

EXAFS spectra acquired at the $3 \mathrm{~d}$ metal $\mathrm{K}$-edges of $\mathrm{Al}_{x}-\mathrm{CrFeCoNi}$ HEAs were analyzed using the reverse Monte Carlo method based on the evolutionary algorithm (EA), which is implemented in the EvAX code $[37,38]$. The advantages of the RMC method are its ability to simultaneously fit a single structural model to several (four in the current case) EXAFS spectra, measured at different absorption edges, and to include into the analysis multiplescattering (MS) effects and contributions from distant and overlapping coordination shells.

The $\mathrm{Cr}, \mathrm{Fe}, \mathrm{Co}$, and $\mathrm{Ni}$ K-edges EXAFS spectra $\chi(k) k^{2}$ were first extracted using a conventional procedure [39] as implemented in the XAESA code [40].

To conduct RMC simulations, a starting structural model (a simulation box) was constructed in a form of the supercell with a size of $4 a \times 4 a \times 4 a$ for the fcc-structured HEA or $5 a \times 5 a \times 5 a$ for the bcc-structured HEA, employing the periodic boundary conditions. The $\mathrm{Al}, \mathrm{Cr}, \mathrm{Fe}, \mathrm{Co}$, and $\mathrm{Ni}$ atoms were randomly distributed in a proper concentration in the fcc (for $\mathrm{Al}_{0.3^{-}}$ $\mathrm{CrFeCoNi} \mathrm{HEA}$ ) or bcc (for $\mathrm{Al}_{3}$-CrFeCoNi HEA) lattices. The experimental values of the lattice parameters $(a=3.572 \AA$ for the fcc lattice and $a=2.877 \AA$ for the bcc lattice) refined from room temperature XRD data were used. The fcc supercell included 256 atoms $(20 \mathrm{Al}, 60 \mathrm{Cr}, 60 \mathrm{Fe}, 57 \mathrm{Co}, 59 \mathrm{Ni})$, whereas the bcc supercell contained 250 atoms $(111 \mathrm{Al}, 34 \mathrm{Cr}, 36 \mathrm{Fe}, 37 \mathrm{Co}, 32 \mathrm{Ni})$.

The details of the RMC/EA method were described previously in Timoshenko et al. [37,38]. In the current study, the number of simultaneously used atomic configurations in the EA method was 32. At each iteration, a new atomic configuration was generated by randomly displacing all atoms in the simulation box with the maximally allowed shift of $0.4 \AA$ to get the best possible agreement between the Morlet wavelet transforms of the experimental and calculated EXAFS spectra $\chi(k) k^{2}$ at the four $3 \mathrm{~d}$ metal edges simultaneously. The calculations were performed in the $k$-space range from 3.0 to $12 \AA^{-1}$ and in the $R$-space range from 1.0 to 6.0 $\AA$. No significant improvement in the residual was observed after 5,000 iterations. As a result of each RMC simulation, a set of atomic coordinates was obtained, which was subsequently used to calculate the partial distribution functions (PDFs) $g(r)$, the mean interatomic distances $r$, and the mean square relative displacements (MSRDs) for each pair of atoms as well as the mean square displacements (MSDs) for each type of atom. To improve statistics, several sets of PDFs (12 for the fcc-structured HEA and 14 for the bcc-structured HEA) were obtained starting from different (independent) structural models. Note, that PDFs obtained from RMC simulations include both thermal and static disorder effects. There is a small difference between $R$-values in Fourier transforms (FT) or WT and $r$-values in $g(r)$ due to the backscattering phase shifts present in the EXAFS equation [39].
The configuration-averaged EXAFS spectra for atomic configurations during RMC simulation were calculated for each type of atom using $a b$ initio real-space multiple-scattering FEFF8.50L code $[41,42]$ including the MS effects up to the $4^{\text {th }}$ order. The scattering potential and partial phase shifts were calculated for each absorption edge only once within the muffintin (MT) approximation $[41,42]$ for the cluster with a radius of $4.8 \AA$, centered at the absorbing metal $(\mathrm{Cr}, \mathrm{Fe}, \mathrm{Co}$, or $\mathrm{Ni})$ atom. Small variations of the cluster potential due to atom displacements during the RMC/EA simulations were neglected. The photoelectron inelastic losses were accounted for within the oneplasmon approximation using the complex exchange-correlation Hedin-Lundqvist potential [43]. The amplitude reduction factor $S_{0}{ }^{2}$ was included in the scattering amplitude [41,42], calculated by the FEFF code, and no additional correction of the EXAFS amplitude was performed. The values of the $E_{0}$ energies for each absorption edge, which are used in the definition of the photoelectron wavenumber $k=\left[\left(2 m_{\mathrm{e}} / \hbar^{2}\right)\left(E-E_{0}\right)\right]^{0.5}$, were set to values that were carefully determined in advance by performing the RMC simulations of reference compounds (pure metallic foils).

\subsection{XANES and XMCD with soft X-rays}

XANES/XMCD experiments at the Fe (690-740 eV), Co (770-820 eV), Ni (840-890 eV), and $\mathrm{Cr}(560-640 \mathrm{eV}) \mathrm{L}_{2,3}$ absorption edges have been performed for the fcc-HEA at the recently installed VEKMAG end-station of PM2 beamline at the Helmholtz-Zentrum Berlin [44]. The absorption spectra for circular polarized X-rays from a bending magnet were recorded by the total electron yield (TEY, drain current) under magnetic fields of $\pm 1.8 \mathrm{~T}$ applied along the incident beam. The experiment was done at low temperature of $10 \mathrm{~K}$ and in $45^{\circ}$ of incidence. The detected signal was normalized on the incoming intensity measured by a Ta coated mesh upstream to the end-station. Prior the measurements the sample was cleaned by Argon sputtering at $1 \mathrm{keV}$ potential for $25 \mathrm{~min}$. For the hysteresis measurements in the field range of $\pm 4 \mathrm{~T}$, the sweep rate of the magnetic field was $2 \mathrm{~T} \cdot \mathrm{min}^{-1}$.

XANES spectra have been also recorded at the $\mathrm{Fe}, \mathrm{Co}, \mathrm{Ni}$, and $\mathrm{Cr} \mathrm{L}_{2,3}$ absorption edges as well as oxygen and aluminum $\mathrm{K}$ absorption edges (520-570 eV and 1,550-1,690 eV, respectively) at the XUV diffractometer end-station of UE46_PGM-1 beamline at the Helmholtz-Zentrum Berlin (BESSY II, Berlin, Germany) $[45,46]$ for both samples. The geometry of the experiment and the detection mode were the same as above $\left(45^{\circ}\right.$ of grazing incidence, TEY mode). The measurements at the $\mathrm{Cr}_{2,3}$ edges and the $\mathrm{O} \mathrm{K}$ edge were done without vacuum protective windows. Spectra have been measured with horizontally polarized X-rays from the third harmonic of the elliptical undulator at RT. TEY of the Pt coated Si mirror before the end-station was used for the normalization of 
the intensity of the incoming photons. EXAFS spectra at the $\mathrm{Al} \mathrm{K}$ edge $(1,550-1,950 \mathrm{eV})$ were also recorded at RT with horizontally polarized X-rays.

\subsection{Magnetic measurements}

Magnetometry measurements were carried out on the fcc-HEA (bulk piece, $52.03 \mathrm{mg}$ ) and bcc-HEA (powder, $36.62 \mathrm{mg}$ ) samples using a commercial magnetic properties measurement system (MPMS, Quantum Design) in magnetic fields up to $7 \mathrm{~T}$ and in a temperature range of $2-360 \mathrm{~K}$. For the fcc-HEA, the vibrating sample magnetometer (VSM) mode with a frequency of $14 \mathrm{~Hz}$ was used. To avoid grain movement in the powder bcc-HEA, the slow direct current (DC) mode was employed. The powder sample was kept in a plastic capsule. The macroscopic magnetic moments per formula unit for both samples were calculated from the measured total magnetic moment (in emu units) using the mass of the sample measured by a microbalance, the molar weight of the sample constituents, and the precise composition of the alloy. The results are given in Table 4.

\section{Results and discussions}

Two single-phase fcc- and bcc-structured $\mathrm{Al}_{x}$-CrFeCoNi HEA alloys were originally characterised by X-ray diffraction upon heating under ambient pressure and hydrostatic compression in diamond anvil cells [23], and exhibited their truly single-phase nature below $600{ }^{\circ} \mathrm{C}$ and up to $60 \mathrm{GPa}$ (see Section 2.1 for details). Upon heating and compression, diffraction patterns did not show any peculiarities that are characteristic for multiphase systems of similar cell parameters [47]. Nevertheless, microscopic study suggests possible local aggregation of elements without a formation of admixture phases or two-phase regions on the macroscopic level [23]. Spectroscopic EXAFS, XANES, and XMCD studies as well as conventional magnetometry were necessary to complement prior findings for a deeper understanding of classical well characterised Al-based HEA systems.

\subsection{EXAFS spectroscopy}

Element-specific EXAFS spectroscopy has been exploited to probe the local environment of $3 \mathrm{~d}$ constituent elements in the alloys under consideration. X-ray absorption spectra recorded at the $\mathrm{K}$ absorption edges of $\mathrm{Cr}, \mathrm{Fe}, \mathrm{Co}$ and $\mathrm{Ni}$ at room temperature for powders of the fcc- and bcc-HEAs as well as the reference foils are shown in Fig. 1 and represent the local coordination of a particular type of atoms in the bulk volume. The shape and positions of EXAFS oscillations found above each absorption edge for the fccHEA (Fig. 1(a)) are very similar and indicate a dominantly homogeneous local environment of all $3 \mathrm{~d}$ constituents adopted in the fcc-structured HEA on the atomic scale. Moreover, these spectra are very close to the spectra of Co and Ni reference foils shown in Fig. 1(c).

Contrary to this, the shape of EXAFS oscillations found for the bcc-HEA (Fig. 1(b)) allows one to split the absorption spectra into two groups: One of them contains the spectra recorded at the Fe and $\mathrm{Cr}$ absorption edges while another one includes the spectra recorded at the absorption edges of $\mathrm{Co}$ and Ni. More specific consideration allows to conclude that spectra from the former group are similar to the spectra of $\mathrm{Fe}$ and $\mathrm{Cr}$ bcc- reference foils with the only suppressed intensity of the main oscillations (Fig. 1(c)) whereas the shapes of EXAFS spectra recorded at the $\mathrm{K}$ edges of $\mathrm{Co}$ and $\mathrm{Ni}$ for the bcc-HEA and reference foils are significantly different.

The EXAFS spectra of the reference foils related to the bcc $(\mathrm{Cr}$, $\mathrm{Fe}$ ) and fcc/hexagonal close packed (hcp) (Ni/Co) crystallographic
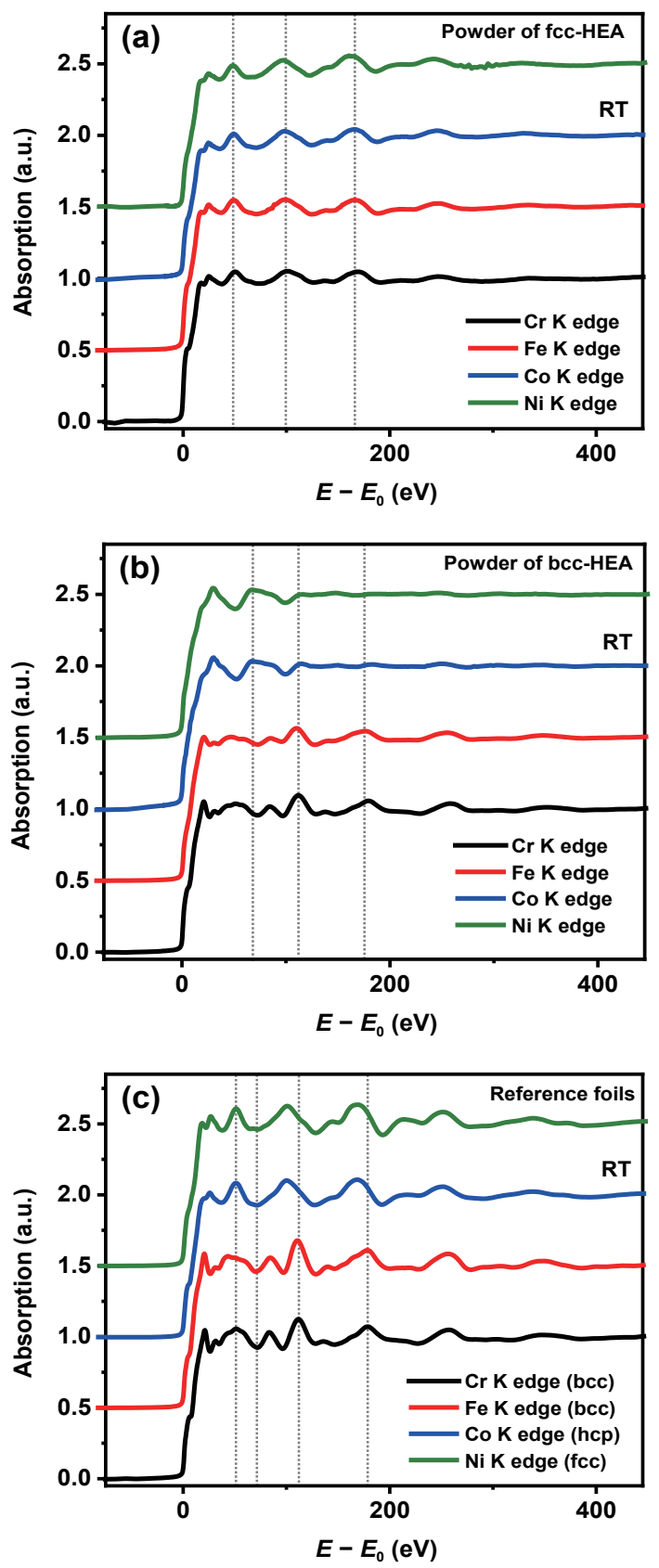

Figure $1 \mathrm{X}$-ray absorption spectra recorded at the $\mathrm{K}$ absorption edges of $\mathrm{Cr}$ $\left(E_{0}=5,989 \mathrm{eV}\right), \mathrm{Fe}\left(E_{0}=7,112 \mathrm{eV}\right), \mathrm{Co}\left(E_{0}=7,709 \mathrm{eV}\right)$, and $\mathrm{Ni}\left(E_{0}=8,333 \mathrm{eV}\right)$ at RT for the fcc- and bcc-HEA samples ((a) and (b)), respectively) and the reference foils (c). $E_{0}$ was determined as the energy corresponded to the first maximum of the first derivative of each particular spectrum. The spectra are normalized to unity and shifted vertically for clarity.

structures can be also divided into two groups as obviously seen from Fig. 1(c) (it is well known that the local environment in the first coordination shell of fcc and hcp crystallographic structures is similar). Comparison with spectra of the fcc- and bcc-HEAs brings to an inference that elements which initially prefer to be arranged in the bcc-structure can be easily adopted in the fccstructured HEA while an adaptation of initially fcc-/hcp-arranged elements in the bcc-structured HEA is much more intricated and could be done only partially. Nevertheless, it does not lead to the phase separation following the results of prior studies where XRD peaks characteristic only for the bcc crystallographic structure were found, and the absence of their segregation under the pressure demonstrates the existence of only a single-phase in this HEA on the macro- and micro-scales.

It should be taken into account that in the studied bcc-HEA, 
there is a large amount of $\mathrm{Al}$ atoms (44 at.\%) among 3d elements (56 at.\%), and $\mathrm{Al}$ atoms are arranged in the fcc crystallographic structure in the bulk; so, there are more than $70 \%$ of atoms (see Section 2.1 for details) for which bcc-arrangement is not typical. As a result, the presence of local inhomogeneities related to these atoms is assumed and will be considered more precisely in the next section.

\subsection{Reverse Monte Carlo simulations}

HEA systems as $\mathrm{Al}_{x}-\mathrm{CrFeCoNi}$ are multi-component compounds where all elements can be potentially positioned in the nearest coordination shell(s) of a particular absorber, and those local structures could be described by a set of PDFs $g(r)$. The experimental EXAFS spectra recorded at the $\mathrm{K}$ absorption edges of $\mathrm{Cr}, \mathrm{Fe}, \mathrm{Co}$, and $\mathrm{Ni}$ (see Fig. 1) are available for further analysis in the $k$-space range from 3.0 to $12 \AA^{-1}$, and the first peak in their FTs that appears between $R=1.2 \AA$ and $R=3.0 \AA$ is quite well isolated. In the case of the fcc structure, it originates from the contributions of the twelve atoms located in the first coordination shell, whereas for the bcc-structure its origin is more complex owing to contributions of the eight atoms in the first and six atoms in the second coordination shells (fourteen atoms in total). According to the Nyquist criterion, the maximum number of parameters allowed in the parametric EXAFS model is

$$
N_{\max }=(2 \Delta k \times \Delta R) / \pi=2 \times 9 \times 1.8 / 3.14 \approx 10
$$

so, no more than three coordination shells could be effectively fitted within a common EXAFS analysis considering a total number of nearest-neighbors $N$, radial distance $r$, and mean square relative displacement $\sigma^{2}$ as free parameters.

In $\mathrm{Al}_{x}$-CrFeCoNi HEA, there are five different types of atoms that can follow not only unimodal distributions; comprising additional distortions due to the local structure relaxations are also possible. Therefore, conventional EXAFS analysis (multi-shell fitting) will lead to unreliable or strongly biased results. The inclusion of additional outer shells in the model will make the analysis even more complicated, because in addition to PDFs, the contributions from many-atom distribution functions (multiplescatterings) should also be taken into account.

Thus, to address the challenging case of HEA, it was worth applying an atomistic simulation approach to EXAFS analysis based on the reverse Monte Carlo method. As the first step, the starting structural model (a supercell with a size defined by the unit cell parameters taken from prior XRD studies) was constructed for the fcc and bcc lattices by randomly distributed atoms taken in the right proportion according to the stoichiometry known from the EDX analysis. Secondly, this structural model was relaxed to take into account disorder effects and to fit the wavelet transforms of experimental EXAFS data simultaneously at the four absorption edges of all $3 \mathrm{~d}$ constituents using the RMC method [48]. As a result, a set of atomic coordinates was obtained and used for the PDF calculations. Finally, the PDFs were used for further local structure analysis (e.g., calculation of mean interatomic distances, coordination numbers, particular atom displacements). More details about the computational procedure and RMC method could be found in Section 2.3.

Two-dimensional WT is a powerful tool to represent the behaviour of EXAFS spectra in the $k$ - and $R$-spaces simultaneously. It allows one to disentangle relative contributions from different types of backscatters in the first and outer coordination shells of the absorbing atom in a complex compound, and it is rather often used as an alternative to the conventional Fourier transform of EXAFS spectra. It not only offers the possibility to visualize the contributions depending on a particular backscatter but for instance, it allows also to distinguish contributions from light and heavy backscattering elements. The theoretical background of WT analysis and some cases of its application could be found elsewhere [48-52].

\subsubsection{Local configurations and PDFs}

The starting and final configurations of atoms used in the RMC simulations for the Al-deficient fcc- and Al-rich bcc-HEAs are presented in Fig. 2. Starting atomic configurations were constructed as $4 a \times 4 a \times 4 a$ and $5 a \times 5 a \times 5 a$ supercells for the fcc$(a=3.572 \AA)$ and bcc-lattices $(a=2.877 \AA)$, respectively. The periodic boundary conditions (PBC) were applied in such a way that the longest interatomic distance that was potentially accessible in the simulations $(\sim 7.1 \AA)$ is larger as compared to the value used during the RMC fitting (6.0 ̊). For both HEA systems, the particular structural model was simultaneously fitted to EXAFS spectra that were measured at four absorption edges. The EXAFS calculations were performed within the multiple-scattering formalism considering the scattering paths up to the fourth-order. This approach has allowed performing a reliable analysis of the experimental EXAFS data and to reconstruct the local environment taking into account thermal and structural (radial and angular) disorders in the first five (or even six) coordination shells around the absorbing $3 \mathrm{~d}$ atom (distances up to $\sim 6.0 \AA$ ). To improve statistics and to achieve a required precision of fitting results, different (independent) starting structural configurations were considered (see Section 2.3).

The comparison of the experimental and RMC-fitted EXAFS $\chi(k) k^{2}$ spectra together with their Fourier and wavelet transforms are shown in Fig. 3 for both HEAs. For the fcc-HEA the

\section{fcc-HEA ( $\mathrm{Al}_{0.3}$-CrFeCoNi)}

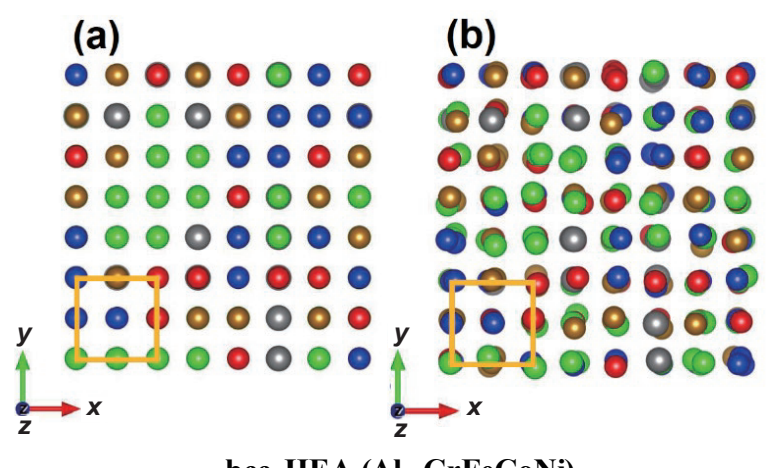

bcc-HEA $\left(\mathrm{Al}_{3}-\mathrm{CrFeCoNi}\right)$

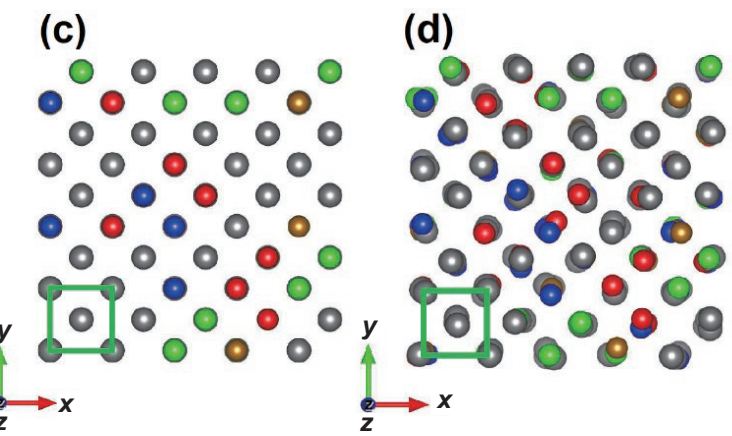

Figure 2 Starting and final configurations of atoms (supercells) used in the RMC simulations for simultaneous fitting of EXAFS spectra of the fcc- ((a) and (b)) and bcc- ((c) and (d)) HEAs at four absorption edges. The supercells were randomly filled with atoms according to the stoichiometry and the periodic boundary conditions were applied. Color scheme: $\mathrm{Al}$ (gray), $\mathrm{Cr}$ (green), $\mathrm{Fe}$ (brown), $\mathrm{Co}$ (blue), $\mathrm{Ni}$ (red). The top views of the supercells are shown (along $z$ direction in chosen $x y z$ coordinates as depicted on the figures). The schematic borders of the fcc- and bcc-unit cells highlight different numbers of atoms in each of them ( 4 and 2 atoms, respectively). 

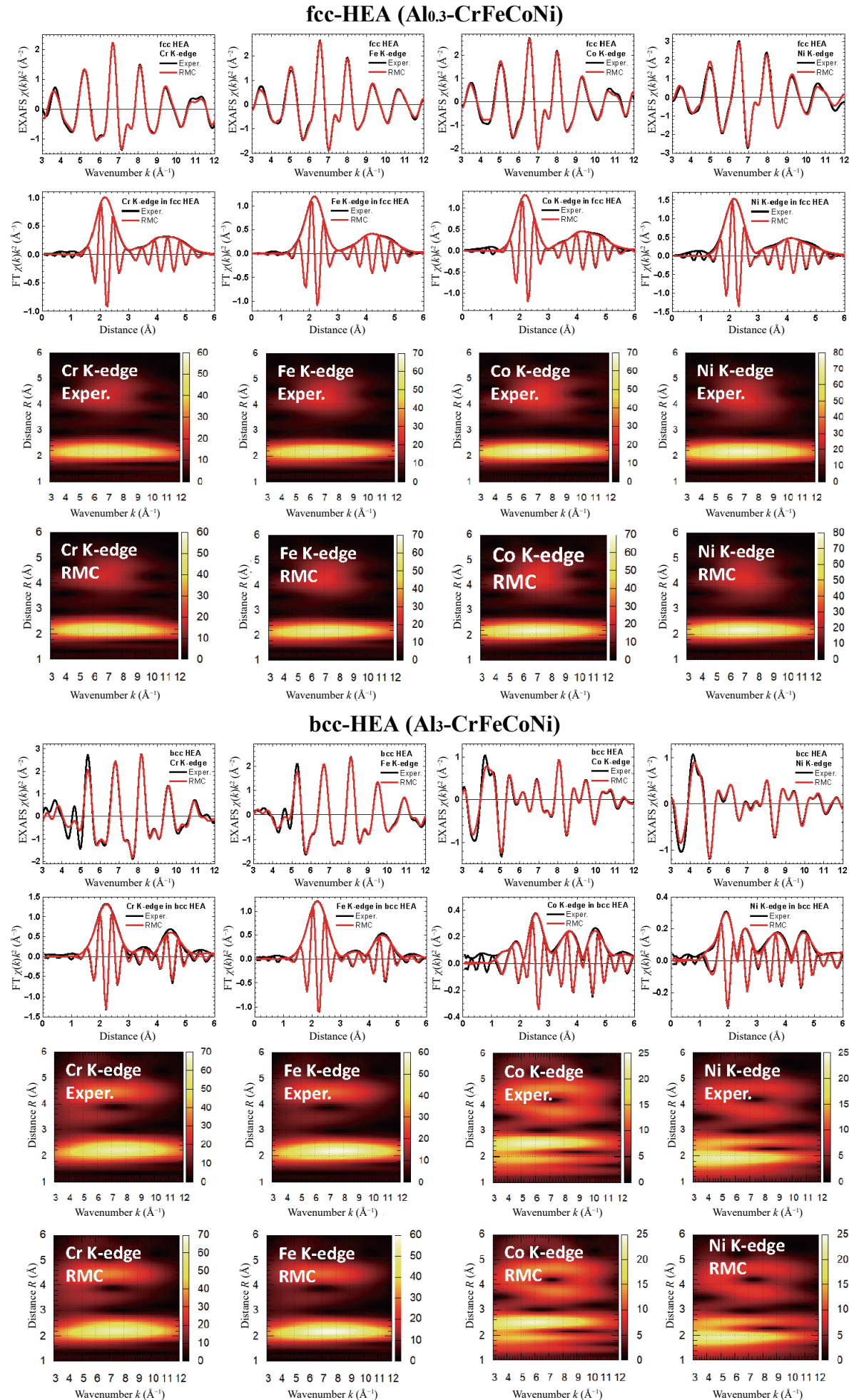

Figure 3 Experimental and RMC-calculated $\mathrm{Cr}, \mathrm{Fe}, \mathrm{Co}$, and Ni K-edge EXAFS spectra $\chi(k) k^{2}$ and their Fourier and Morlet wavelet transforms for the fcc-structured $\mathrm{Al}_{0,3}-\mathrm{CrFeCoNi}$ and the bcc-structured $\mathrm{Al}_{3}-\mathrm{CrFeCoNi}$ HEAs at $300 \mathrm{~K}$.

agreement between the experiment and calculations is very good in both $k$ - and $R$-spaces, and the final structural model represents well all peculiarities in FTs. For the bcc-HEA, the agreement is also reasonably good, despite some deviations at low- $k$ values that reflect a small discrepancy in the most outer shells of the final model (peaks above $4 \AA$ in FTs). Therefore, for both HEA systems and each type of $3 \mathrm{~d}$ absorber, the final structural configurations reproduce well the arrangement of nearest atoms which are responsible for FTs peak(s) in the range of $R=1-3 \AA$.

A set of partial distribution functions extracted from the atomic coordinates obtained in the final structural models for both HEAs is presented in Fig. 4. A clear difference in the characteristic peak positions for the fcc and bcc structures is visible, and the most crucial peculiarities are observed in the region of the first peak for the bcc-structured Al-rich HEA. Note, however, that due to similar scattering amplitudes of $\mathrm{Cr}, \mathrm{Fe}, \mathrm{Co}$, and $\mathrm{Ni}$, these elements cannot be reliably distinguished by EXAFS when they act as neighboring atoms. Thus, similarities in the scattering amplitudes conceal essentially possible differences in the individual PDFs expected due to a partial B2 ordering of 3d constituents: As seen from Figs. 4(e)-4(h), the intensities of peaks that represent contributions of $3 \mathrm{~d}$ nearest-neighbours are very close to each 

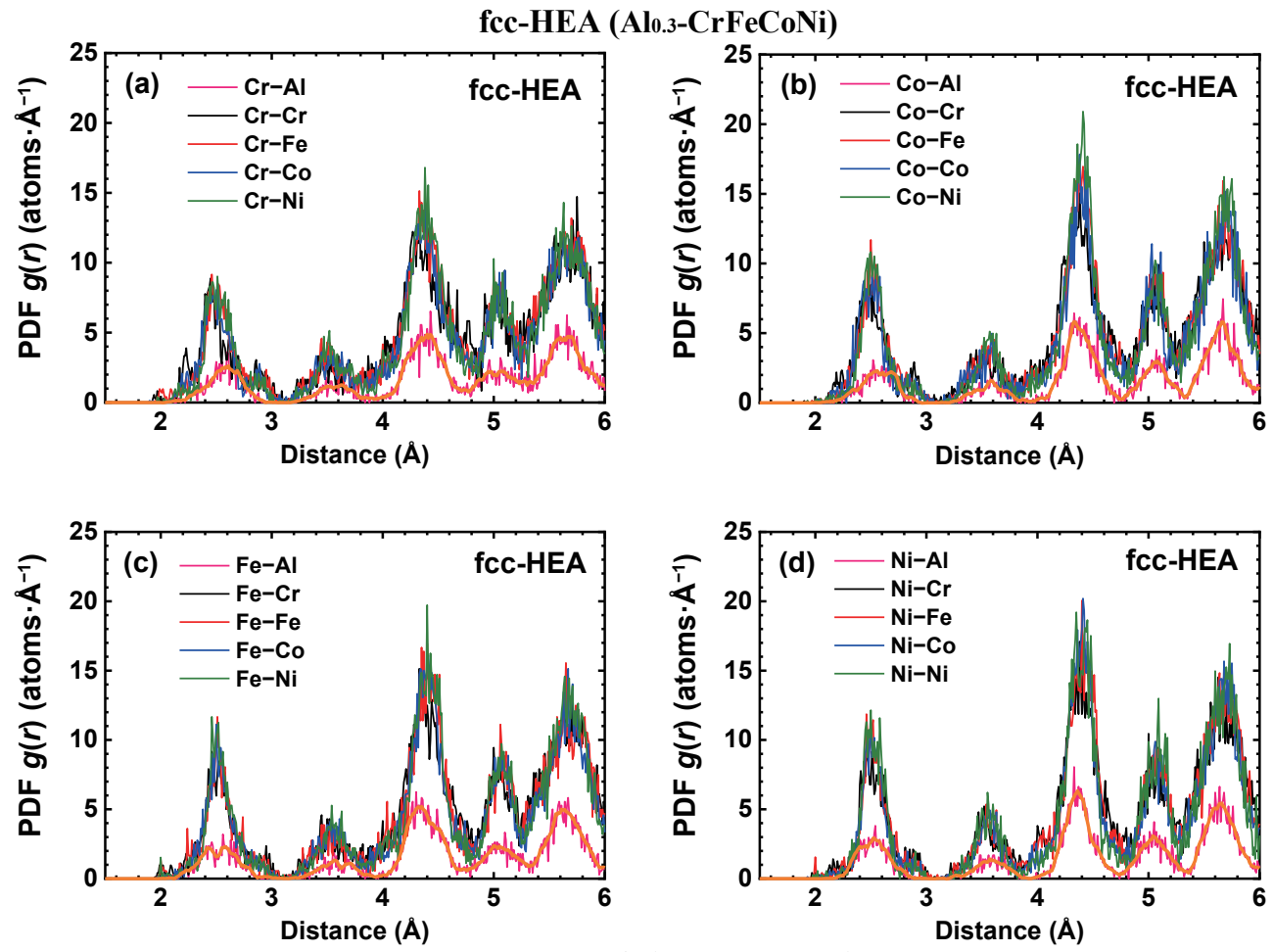

bcc-HEA ( $\left.\mathrm{Al}_{3}-\mathrm{CrFeCoNi}\right)$
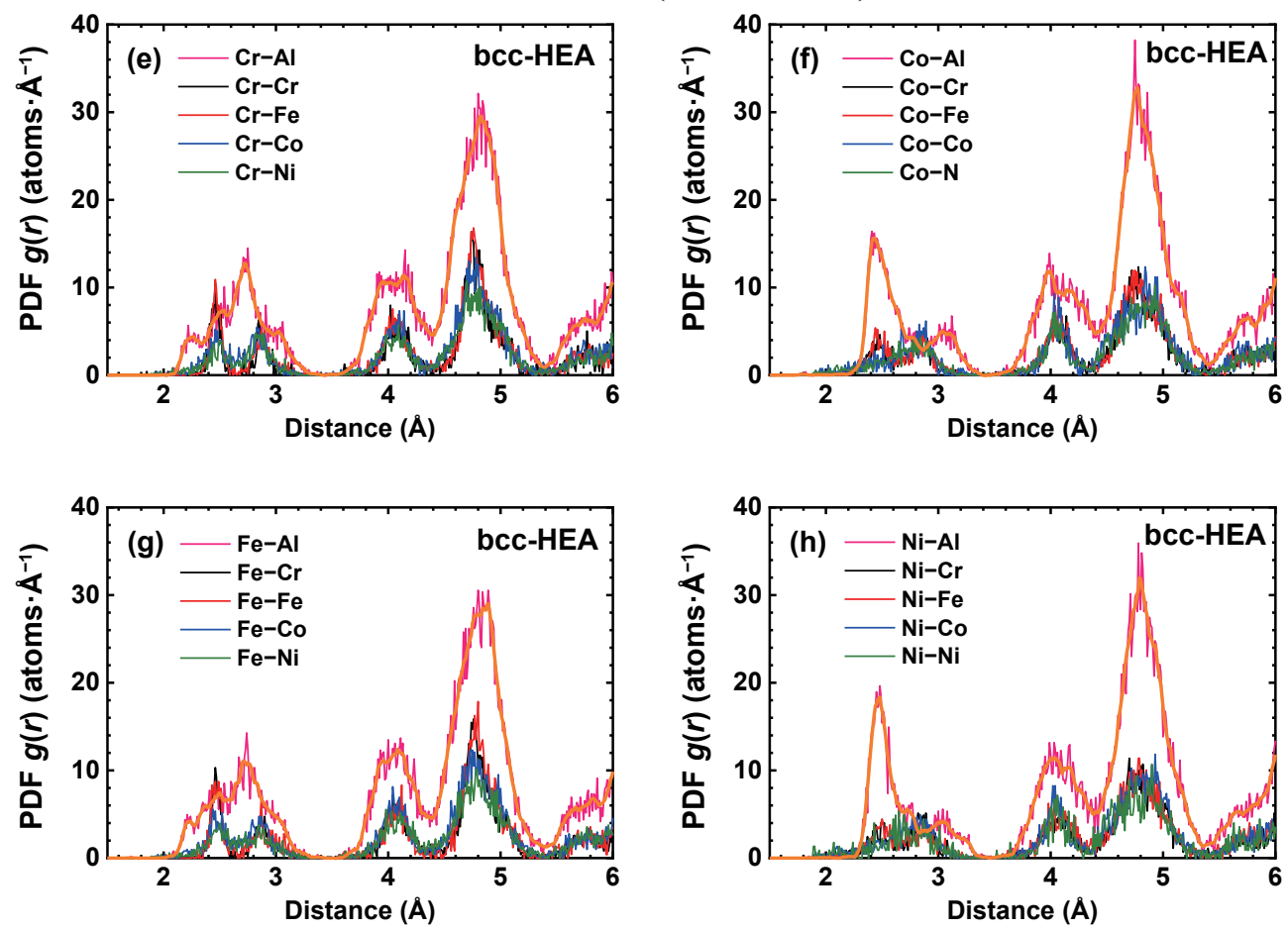

Figure 4 Pair distribution functions $g(r)$ for the fcc- and bcc-HEAs extracted from K-edge EXAFS spectra of Cr ((a) and (e)), Fe ((c) and (g)), Co ((b) and (f)), and Ni ((d) and (h)) using the RMC method. Orange curve is a linear smoothing (over 13 points) of the PDFs related to $\mathrm{Al}$ atoms.

other despite the intensities of $\mathrm{Cr}-\mathrm{Cr}, \mathrm{Cr}-\mathrm{Fe} / \mathrm{Fe}-\mathrm{Cr}, \mathrm{Fe}-\mathrm{Fe}$, $\mathrm{Co}-\mathrm{Cr}$, and $\mathrm{Co}-\mathrm{Fe}$ PDFs are visibly larger around $r=2.5 \AA$ as compared to $\mathrm{Cr}-\mathrm{Co}, \mathrm{Cr}-\mathrm{Ni}, \mathrm{Fe}-\mathrm{Co}, \mathrm{Fe}-\mathrm{Ni}, \mathrm{Co}-\mathrm{Co}$, and $\mathrm{Co}-\mathrm{Ni}$ PDFs. These distinctions could be considered as a signature of the preferential site occupation by a particular type of atoms; nonetheless, strong conclusions should be avoided. An example of distinct differences in PDFs extracted from simulations for a liquid phase of $\mathrm{Al}_{1.3} \mathrm{CoCrCuFeNi}$ alloy could be found in Ref. [7]. Therefore, instead of individual PDFs obtained in the RMC simulations, only PDFs averaged over the four atom types (e.g., $\mathrm{Cr}-\mathrm{Cr}+\mathrm{Cr}-\mathrm{Fe}+\mathrm{Cr}-\mathrm{Co}+\mathrm{Cr}-\mathrm{Ni}$ ) were further analyzed. Also, even though EXAFS spectra at the $\mathrm{Al} \mathrm{K}$ absorption edge could not be measured with a required accuracy up to $12 \AA^{-1}$ due to the presence of the Si K absorption edge (Fig. S2 in the ESM), the $\mathrm{PDF}$ of $\mathrm{Al}$ atoms can be estimated with reasonable accuracy from the structural models obtained through RMC simulations (Fig. S3 in the ESM).

The mean interatomic distances $r$ and the mean square relative displacements $\sigma^{2}$ for each pair of atoms were numerically obtained as the first and second moments of PDFs (see Table 2), whereas the coordination numbers were evaluated as an area under the PDF peaks (see Fig. 5). In such a way, it was found that the 
Table 2 Mean values of interatomic distances $r$ and mean square relative displacements $\sigma^{2}$ calculated numerically as moments of PDFs

\begin{tabular}{|c|c|c|c|c|}
\hline \multirow{2}{*}{ Atom pair } & \multicolumn{2}{|c|}{ fcc-HEA } & \multicolumn{2}{|c|}{ bcc-HEA } \\
\hline & $r(\AA)$ & $\sigma^{2}\left(\AA^{2}\right)$ & $r(\AA)$ & $\sigma^{2}\left(\AA^{2}\right)$ \\
\hline \multirow{2}{*}{$\mathrm{Cr}-\mathrm{Cr} / \mathrm{Fe} / \mathrm{Co} / \mathrm{Ni}$} & \multirow{2}{*}{2.53} & \multirow{2}{*}{0.038} & 2.47 & 0.010 \\
\hline & & & 2.86 & 0.012 \\
\hline \multirow{2}{*}{$\mathrm{Fe}-\mathrm{Cr} / \mathrm{Fe} / \mathrm{Co} / \mathrm{Ni}$} & \multirow{2}{*}{2.54} & \multirow{2}{*}{0.032} & 2.47 & 0.010 \\
\hline & & & 2.87 & 0.015 \\
\hline \multirow{2}{*}{$\mathrm{Co}-\mathrm{Cr} / \mathrm{Fe} / \mathrm{Co} / \mathrm{Ni}$} & \multirow{2}{*}{2.53} & \multirow{2}{*}{0.028} & 2.49 & 0.019 \\
\hline & & & 2.85 & 0.016 \\
\hline \multirow{2}{*}{$\mathrm{Ni}-\mathrm{Cr} / \mathrm{Fe} / \mathrm{Co} / \mathrm{Ni}$} & \multirow{2}{*}{2.54} & \multirow{2}{*}{0.024} & 2.52 & 0.024 \\
\hline & & & 2.86 & 0.015 \\
\hline $\mathrm{Cr} / \mathrm{Fe}-\mathrm{Al}$ & 2.55 & 0.027 & 2.67 & 0.065 \\
\hline \multirow{2}{*}{$\mathrm{Co} / \mathrm{Ni}-\mathrm{Al}$} & \multirow{2}{*}{2.54} & \multirow{2}{*}{0.022} & 2.52 & 0.016 \\
\hline & & & 3.03 & 0.018 \\
\hline
\end{tabular}

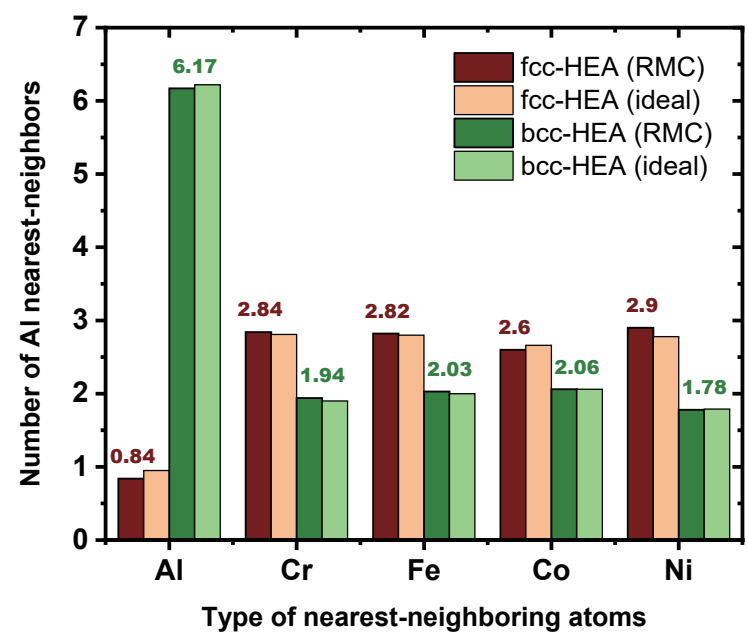

Figure 5 The number of $\mathrm{Al}$ nearest-neighbours extracted from PDFs obtained for the fcc- and bcc-HEAs by the RMC method. A strongly increased number of $\mathrm{Al}-\mathrm{Al}$ nearest-neighbours for the $\mathrm{Al}$-rich bcc-HEA is evident.

distribution of the interatomic distances in the first coordination shell of all atoms in the fcc-HEA is nearly unimodal with the mean distance of about $r=2.53-2.55 \AA$ and the MSRD factor $\sigma^{2}=$ 0.022-0.038 $\AA^{2}$. This suggests a rather close local structure around all metal atoms in the fcc-HEA in agreement with close shapes of EXAFS spectra shown in Fig. 1(a). The situation in the Al-rich bccHEA is more fascinating: As it was already indicated in Section 3.1, there is a well visible difference between $\mathrm{Cr} / \mathrm{Fe}$ (both have bcclattice in the bulk) and $\mathrm{Co} / \mathrm{Ni}$ (which have fcc/hcp lattices) EXAFS spectra and, hence, in their Fourier and wavelet transforms. Therefore, an enlarged relaxation of the local environment can be expected around $\mathrm{Co}$ and $\mathrm{Ni}$ atoms in the bcc-HEA. The difference between the aforementioned groups of atoms is well visible in their first coordination shells (a group of peaks between $r=2 \AA$ and $r=3.5 \AA$ in PDFs) and is less evident in the outer shells: All distributions of $\mathrm{Cr}, \mathrm{Fe}, \mathrm{Co}$, and $\mathrm{Ni}$ in the first coordination shell are bimodal with the peaks centered at $r=2.47-2.52 \AA$ and $r=$ 2.85-2.86 $\AA$, respectively. A distribution of $\mathrm{Al}$ atoms was found to be broad around $\mathrm{Cr}$ and $\mathrm{Fe}$ atoms with the mean interatomic distance $r(\mathrm{Cr} / \mathrm{Fe}-\mathrm{Al})=2.67 \AA$, while it is bimodal around $\mathrm{Co}$ and $\mathrm{Ni}$ atoms with two peaks centered at $r(\mathrm{Co} / \mathrm{Ni}-\mathrm{Al})=2.52 \AA$ and $r(\mathrm{Co} / \mathrm{Ni}-\mathrm{Al})=3.03 \AA$.

The availability of atomic coordinates makes it possible to evaluate quantitatively the MSDs for each type of atoms. Such information is usually retrieved from diffraction data and is not typical for EXAFS data analysis. The values of MSDs were calculated directly from the atomic coordinates of atoms in the simulation box relative to the ideal starting configuration. As follows from Table 3, the elemental constituents in the fcc (bcc)structured HEAs exhibit $\operatorname{MSD}(\mathrm{Al})=0.14(0.21) \AA, \operatorname{MSD}(\mathrm{Cr})=$
$0.23(0.16) \AA, \operatorname{MSD}(\mathrm{Fe})=0.20(0.16) \AA, \operatorname{MSD}(\mathrm{Co})=0.18(0.19) \AA$, and $\operatorname{MSD}(\mathrm{Ni})=0.16(0.20) \AA$, respectively. Thus, it can be concluded that metals having a lattice type in the bulk similar (dissimilar) to ones of HEA experience less (more) relaxation: In the fcc-HEA, Al, Co, and $\mathrm{Ni}$ atoms displace less than $\mathrm{Fe}$ and $\mathrm{Cr}$, whereas in the bcc-HEA, $\mathrm{Cr}$ and Fe displace less than other atoms. Moreover, it seems that the concentration of atoms with dissimilar bulk lattices as $\mathrm{Cr}$ and $\mathrm{Fe}$ in the fcc-HEA (46.7 at.\% in total) and $\mathrm{Al}, \mathrm{Co}$, and $\mathrm{Ni}$ atoms in the bcc-HEA (71.5 at.\% in total) does crucially influence an adaptation of these elements in the HEA structure as it was qualitatively described in Section 3.1.

Finally, considering the starting (ideal) and final (relaxed) configurations, the number of $\mathrm{Al}$ nearest-neighbours in the HEAs

Table 3 Mean square displacements determined directly from the coordinates of atoms in the RMC simulation box

\begin{tabular}{cccc}
\hline & Arrangement in foils & fcc-HEA & bcc-HEA \\
\hline $\mathrm{Al}$ & $\mathrm{fcc}$ & $\mathrm{MSD}(\AA)$ & $\operatorname{MSD}(\AA)$ \\
$\mathrm{Cr}$ & $\mathrm{bcc}$ & $0.141 \pm 0.003$ & $0.212 \pm 0.004$ \\
$\mathrm{Fe}$ & $\mathrm{bcc}$ & $0.199 \pm 0.001$ & $0.155 \pm 0.008$ \\
$\mathrm{Co}$ & $\mathrm{hcp}$ & $0.181 \pm 0.002$ & $0.192 \pm 0.007$ \\
$\mathrm{Ni}$ & $\mathrm{fcc}$ & $0.162 \pm 0.001$ & $0.203 \pm 0.004$ \\
\hline
\end{tabular}

under consideration was determined. As follows from Fig. 5, the ideal and relaxed models suggest very close values for all types of $\mathrm{Al}$ neighbours with an evident difference for the Al-deficient and Al-rich systems: The number of $\mathrm{Al}-\mathrm{Al}$ nearest-neighbours is larger for the Al-rich bcc-HEA while the number of Al-3d metal nearest-neighbours is larger for the fcc-HEA. Taking into account the distribution of $\mathrm{Al}$ atoms around $3 \mathrm{~d}$ elements in both HEAs represented by PDFs and their mean interatomic distances, it may be assumed that hybridization effects associated with the interaction of $\mathrm{Al} 2 \mathrm{p}$ electrons and $3 \mathrm{~d}$ orbitals of transition metals are stronger in the Al-deficient fcc-HEA system.

\subsection{Soft X-ray XANES}

Despite EXAFS spectroscopy revealed only metallic states for all 3d elements in studied HEAs, the surface oxidation does still occur and had to be additionally clarified. To this end, XANES with soft $\mathrm{X}$-rays at the $\mathrm{L}_{2,3}$ absorption edges of $3 \mathrm{~d}$ constituents as well as at the $\mathrm{K}$ absorption edges of $2 \mathrm{p}$ ones has been applied to check the surface and sub-surface volume of the samples, down to several $\mathrm{nm}$. The raw data are presented in Fig. 6, where a different degree of surface oxidation is seen for each constituent of each particular sample.

It comes as a surprise that for the fcc-structured HEA (bulk sample), where a homogeneous local environment was demonstrated by EXAFS, only partial oxidation of Co and almost metallic-like state of $\mathrm{Ni}$ atoms were found while $\mathrm{Fe}$ and $\mathrm{Cr}$ atoms were oxidized in much higher content. The shape of XANES spectra recorded at the $\mathrm{Cr}_{2,3}$ absorption edge is characteristic for $\mathrm{Cr}^{3+}$ ions in $\mathrm{Cr}_{2} \mathrm{O}_{3}$ oxide. A well-pronounced peak at $\sim 532 \mathrm{eV}$ associated with the hybridization of oxygen with $3 \mathrm{~d}$ elements is clearly seen. For the bcc-structured HEA (powder sample), the situation is different: All constituents are in more pronounced oxidized states while the $2 \mathrm{p}-3 \mathrm{~d}$ hybridization peak at the $\mathrm{O} \mathrm{K}$ edge is less prominent. These results are in agreement with outcomes of detailed studies by X-ray photoelectron spectroscopy (XPS) of passive layers at the top of $\mathrm{CrFeCoNi}$ and $\mathrm{Al}_{x}-\mathrm{CrFeCoNi}[53,54]$, which were shown that $\mathrm{Ni}$ atoms from an alloy almost do not participate in the formation of the passive layer while $\mathrm{Cr}$ and $\mathrm{Al}$ 

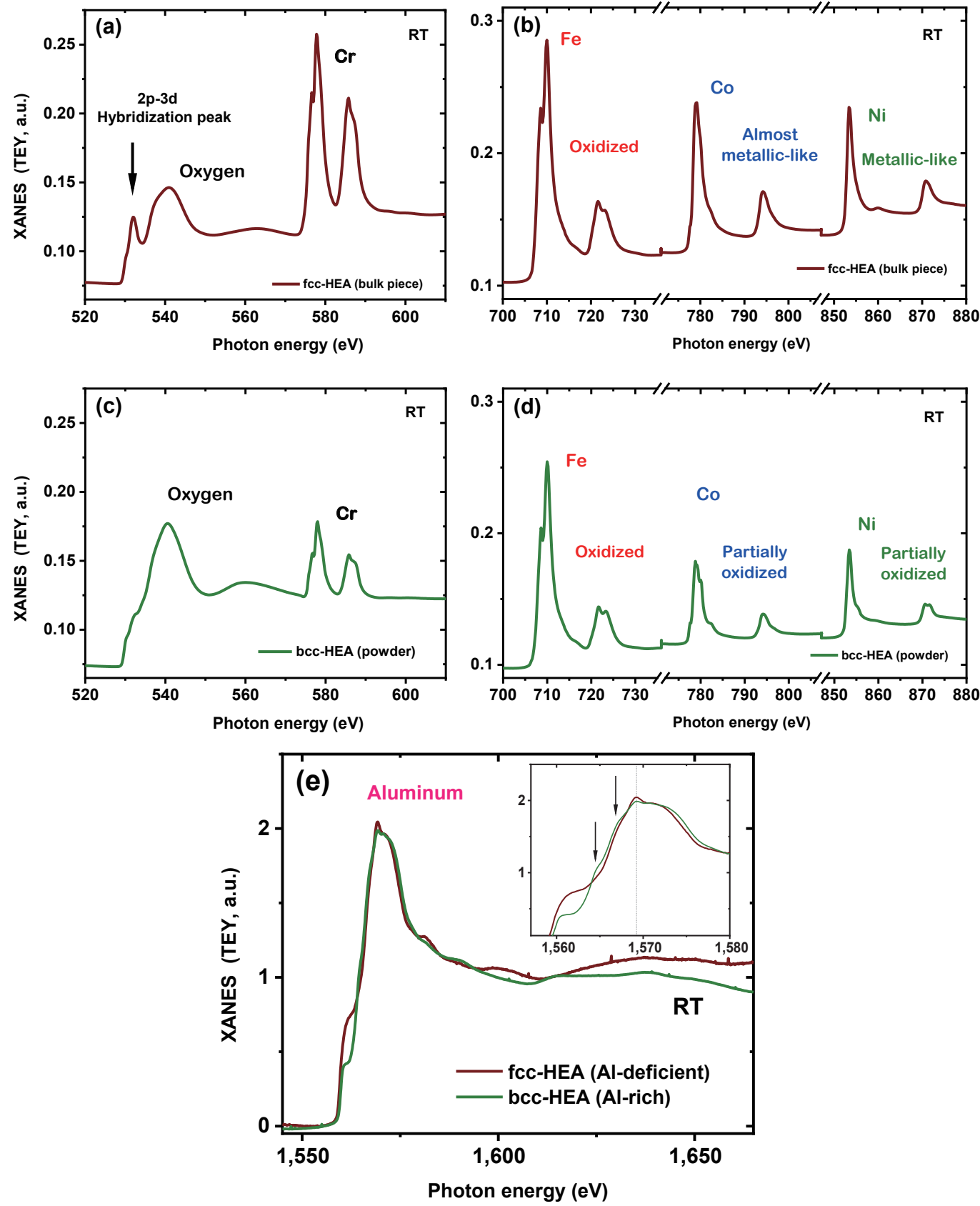

Figure 6 Raw XANES spectra recorded from the fcc- and bcc-HEA samples at RT with horizontally polarized X-rays by TEY at the $\mathrm{L}_{2,3}$ absorption edges of Cr, Fe, $\mathrm{Co}$, and $\mathrm{Ni}((\mathrm{a})-(\mathrm{d}))$ and at the K edge of oxygen ((a) and (c)). XANES spectra recorded at the aluminum K absorption edge by TEY for both HEAs (e) were rescaled for a better comparison of the edge fine structure. The vertical dotted line in the inset indicates the position of the $\mathrm{Al}_{2} \mathrm{O}_{3}$ peak.

atoms actively contribute in it in the form of $\mathrm{Cr}_{2} \mathrm{O}_{3}$ and $\mathrm{Al}_{2} \mathrm{O}_{3}$ oxides. Depending on the stoichiometry these oxides have a certain depth-distribution, and in the case of Al-containing HEAs, Al-enrichment makes the bcc-structured alloys less corrosionresistant. Fe and Co atoms can form different types of oxides and could be in different valence states depending on the elemental composition and oxidation environment.

XANES spectra recorded at the $\mathrm{Al} \mathrm{K}$ absorption edge demonstrate a higher degree of $\mathrm{Al}$ oxidation for the Al-deficient fcc-HEA. Meanwhile, the shoulder in the pre-edge region has a higher intensity which correlates with an assumed higher hybridization between $\mathrm{Al} 2 \mathrm{p}$ and transition metal $3 \mathrm{~d}$ electrons in this sample. Such a shoulder is a characteristic well-pronounced feature of the $\mathrm{Al} \mathrm{K}$ edge absorption spectra observed previously for $\mathrm{FeAl}, \mathrm{CoAl}$, and $\mathrm{NiAl}$ systems experimentally by electron energy loss spectroscopy and it is in agreement with the theoretical first-principals density of states calculations [55]. It was also observed by XANES at the $\mathrm{Al} \mathrm{K}$ edge for $\mathrm{Fe}_{60} \mathrm{Al}_{40}$ thin films in Smekhova et al. (unpublished). For the Al-rich bcc-HEA where a larger amount of $\mathrm{Al}$ atoms is surrounded by $\mathrm{Al}$ nearestneighbours (see Figs. 2 and 5), such a shoulder has smaller intensity; however, a much more pronounced fine structure found at the smaller energy side of the white line reflects dissimilarity in electronic states of $\mathrm{Al}$ atoms in samples studied.

Since the studied HEAs have a different ratio of surface to bulk fractions, a higher degree of surface oxidation found for the bccHEA sample was expected; however, an influence of the crystallographic structure can not be excluded. The results found would trigger further studies related to surface activity of HEAs by X-ray absorption spectroscopy like XANES and XMCD depending on the structure, stoichiometry, and elemental composition of the alloy to complement the existing knowledge acquired by other techniques [56], and will help to understand more deeply some macroscopic findings like corrosion stability or magnetometry results. 


\subsection{Magnetometry}

Conventional magnetometry studies revealed a very different magnetic behaviour of two examined HEAs in terms of saturation magnetization, coercive fields, shape of the hysteresis curve, and their change with temperature (Fig. 7). Both samples were found to be soft ferromagnets with small coercive fields at low temperature of $12 \mathrm{~K}$, although the bcc-HEA sample exhibits a larger coercive field and magnetic moment in saturation as compared to the fcc-structured one. The estimates of the total magnetic moment per formula unit for both systems are given in Table 4. The value of the saturation moment found for the bccHEA in the present work is smaller as compared to another HEA like $\mathrm{Al}_{4}$-CrFeCoMn thin film (bcc) of $1 \mu \mathrm{m}$ thickness at RT [14].

The field dependence of the total moment measured at $360 \mathrm{~K}$ (Figs. 7(a) and 7(b)) shows the presence of magnetic hysteresis and indicates the existence of the long-range ferromagnetic order at temperatures above RT only for the bcc-HEA. The Curie temperature for the fcc sample is obviously much lower. The observed temperature dependencies of the magnetisation and the coercive field (Figs. 7(c) and 7(d)) are very different for these two HEAs.

The derivative $\partial M / \partial T(T)$ of the fcc-HEA sample (see Fig. S4 in the ESM) shows a clear minimum around $\sim 50 \mathrm{~K}$, which is below the temperature of $83 \mathrm{~K}$ found for a minimum of the derivative for Al-free $\mathrm{CrFeCoNi}$ alloy synthesized by arc-melting and than the temperature of $118 \mathrm{~K}$ found for $\mathrm{Cu}_{x}-\mathrm{CrFeCoNi} \mathrm{HEAs}(x=0.5$ and 1.0) [57], where such a minimum was associated with a temperature of ferromagnetic-to-paramagnetic transition. Nevertheless, the temperature dependence of the inverse susceptibility $(\sim 1 / M)$ does not show linear behaviour for the samples studied in the present work as shown in Fig. $\mathrm{S} 4$ in the ESM. That is not surprising because the $3 \mathrm{~d}$ metal ions most likely contribute to the total magnetization with different moments and, more importantly, potentially also with a distribution of Curie temperatures. Therefore, the consideration of such a minimum as a real Curie temperature of the system is questionable.

The temperature dependence of the coercive field, in general, is determined by different effects related to magnetic anisotropy, magnetic defects, various pinning effects, etc., depending on the structure and morphology of the sample studied. The fcc-HEA exhibits a very small coercivity at low temperatures being unobservable at $360 \mathrm{~K}$. This fact is in good agreement with the magnetization as a function of temperature which suggests the absence of ferromagnetism above $T \sim 100 \mathrm{~K}$. For the bcc-HEA, a larger coercivity is found, and it decreases with increasing temperature to very low values. However, the hysteresis curve suggests that at $T=360 \mathrm{~K}$, this compound is still in the ferromagnetic phase, in contrast to the fcc-structured sample. ZFC/FC curves (not shown) do not exhibit a blocking temperature as it would be expected in the case of superparamagnetic particles or spin-glass behaviour. For the temperature dependence of the coercive field, however, many other explanations remain possible: Among them are intra- and inter-granular couplings, complex domain wall pinning mechanism at low temperatures as well as antiferromagnetically coupled $\mathrm{Cr}^{3+}$ ions at the sample surface and $\mathrm{Cr}$ atoms inside the grains.

A larger value of total magnetic moment for the bcc system compared to the fcc one and observed differences in the temperature dependences correlate with a more complex local coordination of $3 \mathrm{~d}$ atoms in the bcc-HEA. Moreover, the presence of local distortions caused by a significant amount of $\mathrm{Al}$ atoms which have $\sim 15 \%$ larger atomic radius than other elements of the alloy may play an important role. The theoretical calculations performed on model $\mathrm{Al}_{x}-\mathrm{CrFeCoNi}$ alloys of different stoichiometry [22] confirm such a general trend.
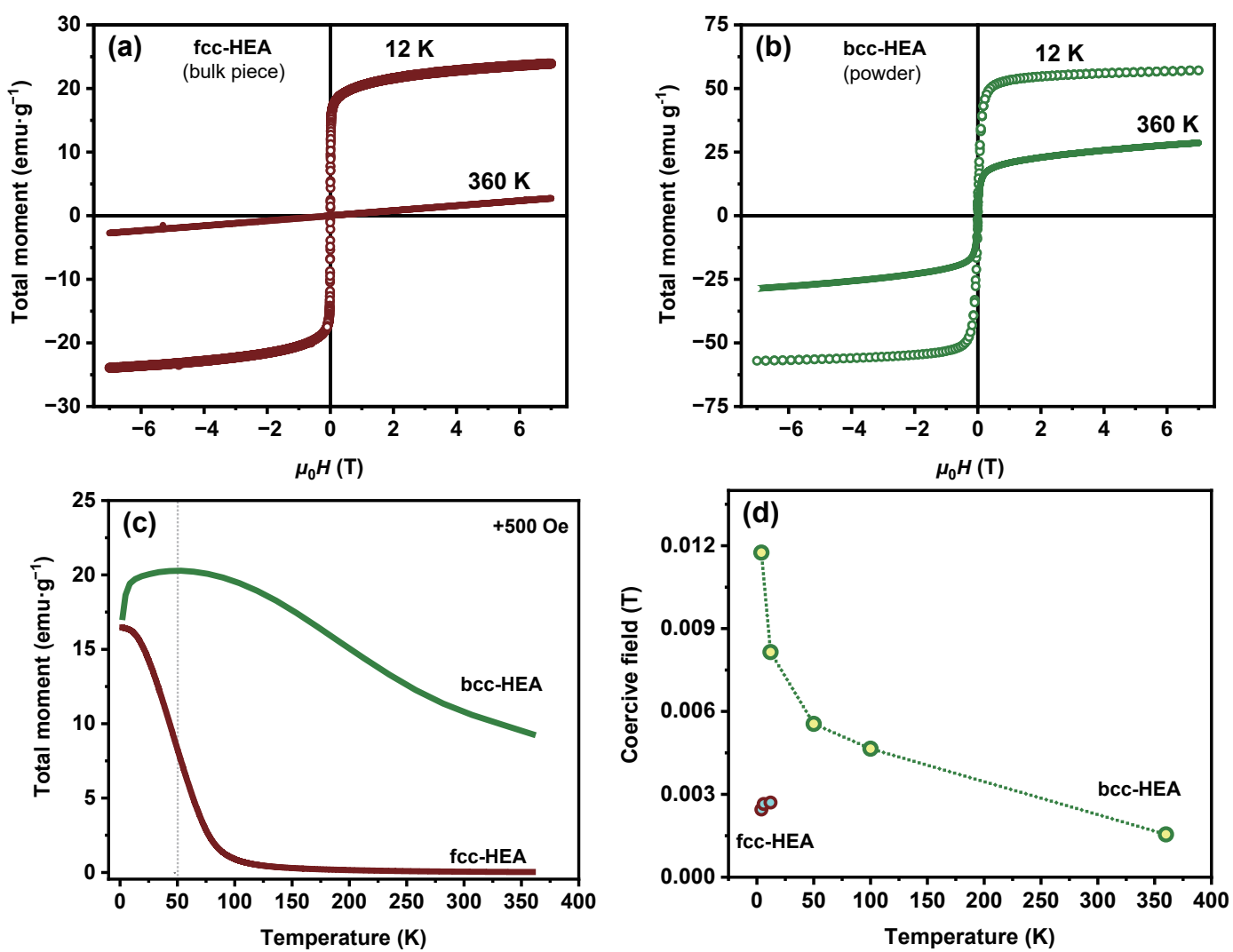

Figure 7 Magnetometry results: Magnetic hysteresis at 12 and $360 \mathrm{~K}$ for the fcc- (a) and bcc- (b) HEAs. The temperature dependence of the magnetization at +500 Oe field (c) and the coercive fields (d). A vertical dashed line at (c) indicates the minimum of the derivative $\partial M(T) / \partial T$ for the fcc-HEA sample. The temperature dependence of the inverse magnetization for both HEAs can be found in ESM. 
Table 4 Magnetic moments per formula unit (in $\mu_{\text {Bohr }}$ ) at $12 \mathrm{~K}$ estimated from the hysteresis curves in a field of $2 \mathrm{~T}$ (the field has been chosen for comparison to the XMCD data, and the moment will be slightly larger at higher fields)

\begin{tabular}{ccc}
\hline fcc-HEA & bcc-HEA \\
\hline \multicolumn{3}{c}{$\mu_{\text {Bohr }}$ per formula unit } \\
\hline $0.91 \pm 0.02$ & $3.1 \pm 0.2$ \\
\hline
\end{tabular}

\subsection{XMCD (after in situ Ar cleaning)}

$\mathrm{X}$-ray magnetic circular dichroism technique is a powerful element-specific tool to probe orbital and spin contributions into the total magnetic moments of a particular type of atoms in a multicomponent system. It is highly sensitive to the valence states and local coordination of probed atoms and can reveal tiny changes in the local environment when other methods are forceless. Herein, we employ XMCD technique to determine magnetic moments of each $3 \mathrm{~d}$ constituent element in the bulk fccHEA sample after cleaning the surface from oxides by in situ Ar sputtering.

XANES and related XMCD asymmetry spectra recorded at the $\mathrm{L}_{2,3}$ absorption edges of $3 \mathrm{~d}$ constituents are shown in Fig. 8(a). The fine structure of both XANES and XMCD spectra demonstrates a metallic character of $\mathrm{Fe}, \mathrm{Co}$, and $\mathrm{Ni}$ atoms while chromium is still in the oxidized $\mathrm{Cr}^{3+}$ state. These results confirm that oxygen is initially present only at the surface of the alloy and not in the bulk volume, and that chromium oxide layer has the largest thickness and/or the strongest $\mathrm{Cr}-\mathrm{O}$ bonds compared to $\mathrm{Co}$ and Fe surface oxides in the studied HEA sample. An important question about the kinetics of these oxides formation and removal from HEAs surface depending on the crystallographic structure and stoichiometry is beyond the scope of the current manuscript.

The sign and the amplitude of the XMCD asymmetry spectra demonstrate the sizable $\mathrm{Fe}$, $\mathrm{Co}$, and Ni magnetic moments which are aligned ferromagnetically with the external magnetic field while $\mathrm{Cr}^{3+}$ ions bear a small magnetic moment which is aligned antiferromagnetically. The absolute values of orbital and spin contributions to each atoms detected magnetic moment were estimated according to well-known optical sum rules analysis [58, 59] and are presented in Table 5. Despite a very small probing depth of soft X-rays (several nm), these values could be considered as estimations of characteristic magnetic moments in the bulk HEA volume.

The orbital $\left(m_{\text {orb_HEA }}\right)$ and effective spin $\left(m_{\text {spin_HEA }}^{*}\right)$ moments of $\mathrm{Fe}, \mathrm{Co}$ and $\mathrm{Ni}$ atoms are reduced compared to their bulk values; however, the ratio of orbital-to-effective-spin moments $\left(m_{\text {orb_HEA }} / m^{*}\right.$ spin_HEA $)$ for Fe and Co in the studied fcc-HEA is enlarged compared to the bulk $\left(m_{\text {orb_bulk }} / m_{\text {spin_bulk }}\right)$. The strongest enlargement of this ratio was found for Co magnetic moment (approx. two times larger) while for $\mathrm{Ni}$ it was found to be the same as in the bulk. In general, an enlargement of orbital-to-effectivespin moments reflects a non-symmetric environment around the absorbers, so, this result is not very surprising taking into account the final configuration shown in Fig. 2(b). The total magnetic moments of $\mathrm{Fe}, \mathrm{Co}$, and $\mathrm{Ni}$ atoms in the studied HEA $\left(m_{\mathrm{tot} H E A}\right)$ considering the number of $3 \mathrm{~d}$ holes as in the bulk volume $\left(n_{3 \text { d_holes_bulk }}\right)$ were found to be approx. $73 \%, 70 \%$, and $97 \%$ compared to their bulk values $\left(m_{\text {tot_bulk }}\right)$, respectively. Such a reduction of total magnetic moments could be a result of hybridisation between $\mathrm{Al}$ and $3 \mathrm{~d}$ transition metals, which is rather strong in the studied fcc-HEA as it was mentioned in Sections 3.2.1 and 3.3 above.

The estimation of orbital, effective spin, and total magnetic moments of $\mathrm{Cr}^{3+}$ ions at the surface of the fcc-HEA provided the values of $(0.011 \pm 0.002) \mu_{\text {Bohr }}(-0.05 \pm 0.01) \mu_{\text {Bohr }}$ and $(-0.039 \pm$ 0.008) $\mu_{\text {Bohr }}$, respectively. The element-specific hysteresis loops
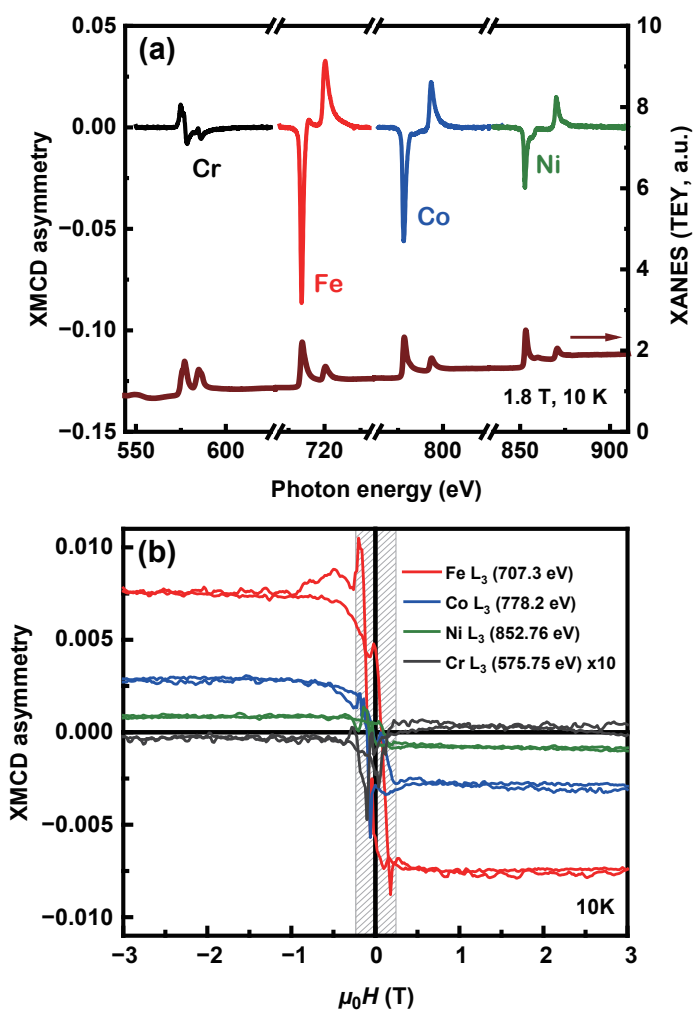

Figure 8 XANES and XMCD asymmetry spectra recorded at the $\mathrm{Cr}, \mathrm{Fe}$, $\mathrm{Co}$, and $\mathrm{Ni}_{2,3}$ absorption edges at $10 \mathrm{~K}$ for the in situ cleaned fcc-HEA (a) and element-specific hysteresis curves recorded at the maximum of the XMCD signals as indicated (b). XMCD asymmetry spectra were calculated as $(\mathrm{TEY}(+1.8 \mathrm{~T})-\operatorname{TEY}(-1.8 \mathrm{~T})) /((\mathrm{TEY}(+1.8 \mathrm{~T})+\operatorname{TEY}(-1.8 \mathrm{~T})) / 2)$. The patterned area shows the signal instability region at small magnetic fields.

measured at energies corresponded to the maximum of the $\mathrm{XMCD}$ signal for $\mathrm{Fe}, \mathrm{Co}$, and $\mathrm{Ni}$ have shown a saturation of the magnetic moments at magnetic fields smaller than $0.5 \mathrm{~T}$ (see Fig. 8(b)).

\section{Conclusion}

Applying complementary element-specific X-ray absorption spectroscopy techniques to studies of local coordination, electronic states, and magnetic behaviour of constituent atoms in multicomponent high-entropy alloys in addition to X-ray diffraction and conventional magnetometry makes it possible to get more clear insights about processes that determine the macroscopic behaviour of HEAs depending on their crystallographic structure and stoichiometry. It was demonstrated that it is feasible to employ the EXAFS technique in conjunction with the reverse Monte Carlo based analysis to reveal key peculiarities of individual atoms' nearest-neighbour arrangements on the atomic scale, and to estimate quantitatively a degree of local atomic structure relaxation in systems commonly considered as uniform. Besides, local inhomogeneities attributed to a particular type of atoms can be proven. These methods could be further used to check the limits of atoms adaptation possible in single-phase HEAs before the phase separation; especially in cases, when individual constituents possess crystallographic structures in the bulk dissimilar to one realised in the multicomponent system. The methodology used is well adapted to studies of the short-range order in bimetallic nanocatalysts $[65,66]$ and can be extended to the case of nanostructured HEAs [67].

A degree of surface atoms oxidation and hybridization effects between constituents probed by soft X-rays have to be taken into account for the explanation of enhanced corrosion stability and 
Table 5 Element-specific orbital $\left(m_{\text {or__HEA }}\right)$ and effective spin $\left(m_{\text {spin_HEA }}^{*}\right)$ contributions to total magnetic moments $\left(m_{\text {to__HEA }}\right)$ of $3 \mathrm{~d}$ atoms in $\mu_{\text {Bohr }}$ in the in situ cleaned fcc-HEA at 10 Kestimated by sum rules analysis, and corresponded bulk values of magnetic moments ( $\left.m_{\text {tot_bulk }}\right)$ and numbers of $3 \mathrm{~d}$ holes $\left(n_{3 \mathrm{~d} \_ \text {_holes_bulk }}\right)$

\begin{tabular}{|c|c|c|c|}
\hline & \multicolumn{3}{|c|}{ fcc- $\mathrm{Al}_{0.3} \mathrm{CrFeCoNi}$ (cleaned in situ) } \\
\hline & $\mathrm{Fe}$ & Co & $\mathrm{Ni}$ \\
\hline$m_{\text {orb_HEA }}$ (per 3d_hole) & $0.030 \pm 0.006$ & $0.078 \pm 0.016$ & $0.036 \pm 0.007$ \\
\hline$m_{\text {spin_HEA }}^{\star}($ per 3d_hole) & $0.45 \pm 0.09$ & $0.40 \pm 0.08$ & $0.36 \pm 0.07$ \\
\hline$m_{\text {orb_HEA }} / m_{\text {spin_HEA }}^{\star}$ & 0.067 & 0.194 & 0.100 \\
\hline$m_{\text {orb_bulk }} / m_{\text {spin_bulk }}^{*}$ & $0.042(\mathrm{bcc})$ & 0.099 (hcp) & $0.100(\mathrm{fcc})$ \\
\hline$m_{\text {tot_HEA }}($ per 3d_hole) & $0.48 \pm 0.10$ & $0.48 \pm 0.09$ & $0.40 \pm 0.08$ \\
\hline$m_{\text {tot_bulk }}^{\text {b,c }}($ per 3d_hole) & 0.65 & 0.69 & 0.41 \\
\hline$n_{3 \text { d__holes_bulk }}{ }^{\mathrm{d}}$ & 3.4 & 2.5 & 1.5 \\
\hline$m_{\text {tot_HEA }}$ & $1.63 \pm 0.33$ & $1.20 \pm 0.24$ & $0.60 \pm 0.12$ \\
\hline$m_{\text {tot_bulk }}{ }^{\mathrm{b}}$ & 2.22 & 1.72 & 0.62 \\
\hline Ratio $m_{\text {tot_HEA }} / m_{\text {tot_bulk }}$ & 0.73 & 0.70 & 0.97 \\
\hline
\end{tabular}

${ }^{\mathrm{a}}$ Reference [60]. ${ }^{\mathrm{b}}$ Reference [61]. ' $\mathrm{C}$ References [62, 63]. ${ }^{\mathrm{d}}$ Reference [64].

structure-dependent magnetic properties of HEAs. Furthermore, they can be also helpful for understanding degradation effects, changes in magnetic properties as well as electrochemistry and catalytic activities of HEAs with a varied set of components. Element-specific magnetic studies performed on oxide-free HEAs will allow an even deeper understanding of these interdependencies.

In such a way, it will be possible to build compositionstructure-magnetic properties diagrams and to understand general trends not only in bulk high-entropy alloys but also in a broad range of other multicomponent systems that expected to reveal phase transitions between $\mathrm{fcc}, \mathrm{bcc}$, and hcp structures under heating, compression, or torsion as well as in high-entropy oxides and ceramics in their bulk and nanostructured modifications.

\section{Acknowledgements}

The authors thank the Helmholtz-Zentrum Berlin for the provision of access to synchrotron radiation facilities and allocation of synchrotron radiation at the PM2-VEKMAG, BAMline, and UE46_PGM-1 beamlines of BESSY II at HZB as well as measurement time for magnetometry at HZB CoreLab for Quantum Materials. A. S. acknowledges personal funding from CALIPSOplus project (the Grant Agreement no. 730872 from the EU Framework Programme for Research and Innovation HORIZON 2020). The financial support for the VEKMAG project and the PM2-VEKMAG beamline by the German Federal Ministry for Education and Research (Nos. BMBF 05K10PC2, 05K10WR1, 05K10KE1) and by HZB is cordially acknowledged by all co-authors. Steffen Rudorff is acknowledged for technical support. Institute of Solid State Physics, University of Latvia as the Center of Excellence has received funding from the European Union's Horizon 2020 Framework Programme H2020WIDESPREAD-01-2016-2017-TeamingPhase2 under grant agreement No. 739508, project CAMART2.

Funding note: Open Access funding enabled and organized by Projekt DEAL

Electronic Supplementary Material: Supplementary material (powder diffraction patterns at ambient conditions, EXAFS data recorded at the $\mathrm{Al} \mathrm{K}$ edge, partial distribution functions of aluminum atoms and temperature dependence of inverse magnetisation together with a magnetization derivative) is available in the online version of this article at https://doi.org/ 10.1007/s12274-021-3704-5.

Open Access This article is licensed under a Creative Commons Attribution 4.0 International License, which permits use, sharing, adaptation, distribution and reproduction in any medium or format, as long as you give appropriate credit to the original author(s) and the source, provide a link to the Creative Commons licence, and indicate if changes were made.

The images or other third party material in this article are included in the article's Creative Commons licence, unless indicated otherwise in a credit line to the material. If material is not included in the article's Creative Commons licence and your intended use is not permitted by statutory regulation or exceeds the permitted use, you will need to obtain permission directly from the copyright holder.

To view a copy of this licence, visit http://creativecommons. org/licenses/by/4.0/.

\section{References}

[1] Cantor, B.; Chang, I. T. H.; Knight, P.; Vincent, A. J. B. Microstructural development in equiatomic multicomponent alloys. Mater. Sci. Eng. A 2004, 375-377, 213-218.

[2] Yeh, J. W. Recent progress in high-entropy alloys. Ann. Chim. Sci. Mat. 2006, 31, 633-648.

[3] Ye, Y. F.; Wang, Q.; Lu, J.; Liu, C. T.; Yang, Y. High-entropy alloy: Challenges and prospects. Mater Today 2016, 19, 349-362.

[4] George, E. P.; Raabe, D.; Ritchie, R. O. High-entropy alloys. Nat Rev. Mater. 2019, 4, 515-534.

[5] Yeh, J. W.; Lin, S. J.; Chin, T. S.; Gan, J. Y.; Chen, S. K.; Shun, T. T.; Tsau C. H.; Chou S. Y. Formation of simple crystal structures in $\mathrm{Cu}-\mathrm{Co}-\mathrm{Ni}-\mathrm{Cr}-\mathrm{Al}-\mathrm{Fe}-\mathrm{Ti}-\mathrm{V}$ alloys with multiprincipal metallic elements. Metall. Mater. Trans. A 2004, 35, 2533-2536.

[6] Dahlborg, U.; Cornide, J.; Calvo-Dahlborg, M.; Hansen, T. C.; Fitch, A.; Leong, Z.; Chambreland, S.; Goodall, R. Structure of some $\mathrm{CoCrFeNi}$ and $\mathrm{CoCrFeNiPd}$ multicomponent HEA alloys by diffraction techniques. J. Alloys Compd. 2016, 681, 330-341.

[7] Santodonato, L. J.; Zhang, Y.; Feygenson, M.; Parish, C. M.; Gao, M. C.; Weber, R. J. K.; Neuefeind, J. C.; Tang, Z.; Liaw, P. K. Deviation from high-entropy configurations in the atomic distributions of a multi-principal-element alloy. Nat. Commun. 2015, 6, 5964.

[8] Li, D. Y.; Li, C. X.; Feng, T.; Zhang, Y. D.; Sha, G.; Lewandowski, J. J.; Liaw, P. K.; Zhang, Y. High-entropy $\mathrm{Al}_{0.3} \mathrm{CoCrFeNi}$ alloy fibers with high tensile strength and ductility at ambient and cryogenic temperatures. Acta Mater. 2017, 123, 285-294. 
[9] Li, Z. Z.; Zhao, S. T.; Ritchie, R. O.; Meyers, M. A. Mechanical properties of high-entropy alloys with emphasis on face-centered cubic alloys. Prog. Mater. Sci. 2019, 102, 296-345.

[10] Schneeweiss, O.; Friák, M.; Dudová, M.; Holec, D.; Šob, M.; Kriegner, D.; Holý, V.; Beran, P.; George, E. P.; Neugebauer, J. et al. Magnetic properties of the $\mathrm{CrMnFeCoNi}$ high-entropy alloy. Phys. Rev. B 2017, 96, 014437.

[11] Gaertner, D.; Abrahams, K.; Kottke, J.; Esin, V. A.; Steinbach, I.; Wilde, G.; Divinski S. V. Concentration-dependent atomic mobilities in FCC CoCrFeMnNi high-entropy alloys. Acta Mater. 2019, 166, $357-370$.

[12] Gao, M. C.; Yeh, J. W.; Liaw, P. K.; Zhang, Y. High-Entropy Alloys: Fundamentals and Applications; Springer: Cham, 2016.

[13] Pogrebnjak, A. D.; Bagdasaryan, A. A.; Yakushchenko, I. V.; Beresnev, V. M. The structure and properties of high-entropy alloys and nitride coatings based on them. Russ. Chem. Rev. 2014, 83, 1027-1061.

[14] Marshal, A.; Pradeep, K. G.; Music, D.; Wang, L.; Petracic, O.; Schneider, J. M. Combinatorial evaluation of phase formation and magnetic properties of $\mathrm{FeMnCoCrAl}$ high entropy alloy thin film library. Sci. Rep. 2019, 9, 7864.

[15] Niu, C.; Zaddach, A. J.; Oni, A. A.; Sang, X.; Hurt, J. W.; LeBeau, J. M.; Koch, C. C.; Irving, D. L. Spin-driven ordering of $\mathrm{Cr}$ in the equiatomic high entropy alloy NiFeCrCo. Appl. Phys. Lett. 2015, 106, 161906.

[16] Meisenheimer, P. B.; Williams, L. D.; Sung, S. H.; Gim, J.; Shafer, P.; Kotsonis, G. N.; Maria, J. P.; Trassin, M.; Hovden, R.; Kioupakis, E. et al. Magnetic frustration control through tunable stereochemically driven disorder in entropy-stabilized oxides. Phys. Rev. Mater. 2019, 3, 104420.

[17] Kotsonis, G. N.; Meisenheimer, P. B.; Miao, L. X.; Roth, J.; Wang, B. M.; Shafer, P.; Engel-Herbert, R.; Alem, N.; Heron, J. T.; Rost, C. M. et al. Property and cation valence engineering in entropystabilized oxide thin films. Phys. Rev. Mater. 2020, 4, 100401(R).

[18] Tung, C. C.; Yeh, J. W.; Shun. T. T.; Chen, S. K.; Huang, Y. S.; Chen, H. C. On the elemental effect of AlCoCrCuFeNi high-entropy alloy system. Mater. Lett. 2007, 61, 1-5.

[19] Wang, W. R.; Wang, W. L.; Wang, S. C.; Tsai, Y. C.; Lai, C. H.; Yeh, J. W. Effects of Al addition on the microstructure and mechanical property of $\mathrm{Al}_{x} \mathrm{CoCrFeNi}$ high-entropy alloys. Intermetallics 2012, 26, 44-51.

[20] Li, C.; Li, J. C.; Zhao, M.; Jiang, Q. Effect of aluminum contents on microstructure and properties of $\mathrm{Al}_{x} \mathrm{CoCrFeNi}$ alloys. J. Alloys Compd. 2010, 504, S515-S518.

[21] Kao, Y. F.; Chen, T. J.; Chen, S. K.; Yeh, J. W. Microstructure and mechanical property of as-cast, -homogenized, and-deformed $\mathrm{Al}_{x} \mathrm{CoCrFeNi}(0 \leq x \leq 2)$ high-entropy alloys. J. Alloys Compd. 2009, 488, 57-64.

[22] Cieslak, J.; Tobola, J.; Reissne, M. The effect of bcclfcc phase preference on magnetic properties of $\mathrm{Al}_{x} \mathrm{CrFeCoNi}$ high entropy alloys. Intermetallics 2020, 118, 106672.

[23] Yusenko, K. V.; Riva, S.; Crichton, W. A.; Spektor, K.; Bykova, E.; Pakhomova, A.; Tudball, A.; Kupenko, I.; Rohrbach, A.; Klemme, S. et al. High-pressure high-temperature tailoring of high entropy alloys for extreme environments. J. Alloys Compd. 2018, 738, 491-500.

[24] Riva, S.; Mehraban, S.; Lavery, N. P.; Schwarzmüller, S.; Oeckler, O.; Brown, S. G. R.; Yusenko K. V. The effect of scandium ternary intergrain precipitates in Al-containing high-entropy alloys. Entropy 2018, 20, 488.

[25] Riva, S.; Tudball, A.; Mehraban, S.; Lavery, N. P.; Brown, S. G. R.; Yusenko, K. V. A novel high-entropy alloy-based composite material. J. Alloys Compd. 2018, 730, 544-551.

[26] Zhang, F. X.; Tong, Y.; Jin, K.; Bei, H. B.; Weber, W. J.; Zhang, Y. W. Lattice distortion and phase stability of Pd-doped $\mathrm{NiCoFeCr}$ solid-solution alloys. Entropy 2018, 20, 900.

[27] Zhang, F. X.; Tong, Y.; Jin, K.; Bei, H. B.; Weber, W. J.; Huq, A.; Lanzirotti, A.; Newville, M.; Pagan, D. C.; Ko, J. Y. P. Chemical complexity induced local structural distortion in $\mathrm{NiCoFeMnCr}$ highentropy alloy. Mater. Res. Lett. 2018, 6, 450-455.

[28] Oh, H. S.; Ma, D. C.; Leyson, G. P.; Grabowski, B.; Park, E. S.; Körmann, F.; Raabe, D. Lattice distortions in the FeCoNiCrMn high entropy alloy studied by theory and experiment. Entropy 2016, 18, 321.

[29] Maulik, O.; Patra, N.; Bhattacharyya, D.; Jha, S. N.; Kumar, V. Local atomic structure investigation of $\mathrm{AlFeCuCrMg}_{x}(0.5,1,1.7)$ high entropy alloys: X-ray absorption spectroscopy study. Solid State Commun. 2017, 252, 73-77.

[30] Körmann, F.; Ma, D.; Belyea, D. D.; Lucas, M. S.; Miller, C. W.; Grabowski, B.; Sluiter, M. H. F. "Treasure maps" for magnetic highentropy-alloys from theory and experiment. Appl. Phys. Lett. 2015, $107,142404$.

[31] Cieslak, J.; Tobola, J.; Przewoznik, J.; Berent, K.; Dahlborg, U.; Cornide, J.; Mehraban, S.; Lavery, N.; Calvo-Dahlborg, M. Multiphase nature of sintered vs. arc-melted $\mathrm{Cr}_{x} \mathrm{AlFeCoNi}$ high entropy alloys-experimental and theoretical study. J. Alloys Compd. 2019, $801,511-519$.

[32] Wang, H. L.; Gao, T. X.; Niu, J. Z.; Shi, P. J.; Xu, J.; Wang, Y. Microstructure, thermal properties, and corrosion behaviors of FeSiBAlNi alloy fabricated by mechanical alloying and spark plasma sintering. Int. J. Miner. Metall. Mater. 2016, 23, 77-82.

[33] Mohanty, S.; Gurao, N. P.; Biswas, K. Sinter ageing of equiatomic $\mathrm{Al}_{20} \mathrm{Co}_{20} \mathrm{Cu}_{20} \mathrm{Zn}_{20} \mathrm{Ni}_{20}$ high entropy alloy via mechanical alloying. Mater. Sci. Eng. A 2014, 617, 211-218.

[34] Zhang, A. J.; Han, J. S.; Meng, J. H.; Su, B.; Li, P. D. Rapid preparation of $\mathrm{AlCoCrFeNi}$ high entropy alloy by spark plasma sintering from elemental powder mixture. Mater. Lett. 2016, 181, $82-85$.

[35] Tracy, C. L.; Park, S.; Rittman, D. R.; Zinkle, S. J.; Bei, H. B.; Lang, M.; Ewing, R. C.; Mao, W. L. High pressure synthesis of a hexagonal close-packed phase of the high-entropy alloy CrMnFeCoNi. Nat. Commun. 2017, 8, 15634.

[36] Riesemeier, H.; Ecker, K.; Görner, W.; Müller, B. R.; Radtke, M.; Krumrey, M. Layout and first XRF applications of the BAMline at BESSY II. X-Ray Spectrom. 2005, 34, 160-163.

[37] Timoshenko, J.; Kuzmin, A.; Purans, J. Reverse Monte Carlo modeling of thermal disorder in crystalline materials from EXAFS spectra. Comput. Phys. Commun. 2012, 183, 1237-1245.

[38] Timoshenko, J.; Kuzmin, A.; Purans, J. EXAFS study of hydrogen intercalation into $\mathrm{ReO}_{3}$ using the evolutionary algorithm. J. Phys. Condens. Matter 2014, 26, 055401.

[39] Kuzmin, A.; Chaboy, J. EXAFS and XANES analysis of oxides at the nanoscale. IUCrJ. 2014, 1, 571-589.

[40] Xaesa, v0.04; GitHub: 2021. https://github.com/aklnk/xaesa (accessed Nov 1, 2020).

[41] Ankudinov, A. L.; Ravel, B.; Rehr, J. J.; Conradson, S. D. Realspace multiple-scattering calculation and interpretation of X-rayabsorption near-edge structure. Phys. Rev. B. 1998, 58, 7565-7576.

[42] Rehr, J. J.; Albers, R. C. Theoretical approaches to X-ray absorption fine structure. Rev. Mod. Phys. 2000, 72, 621-654.

[43] Hedin, L.; Lundqvist, B. I. Explicit local exchange-correlation potentials. J. Phys. C: Solid State Phys. 1971, 4, 2064-2083.

[44] Noll, T.; Radu, F. In Proceedings of the Mechanical Engineering Design of Synchrotron Radiation Equipment and Instrumentation Conference (MEDSI' 16), Barcelona, 2016 2017; pp 370-373.

[45] Englisch, U.; Rossner, H.; Maletta, H.; Bahrdt, J.; Sasaki, S.; Senf, F.; Sawhney, K. J. S.; Gudat, W. The elliptical undulator UE46 and its monochromator beam-line for structural research on nanomagnets at BESSY-II. Nucl. Instrum. Methods Phys. Res. A: Accel. Spectr., Detect. Ass. Equip. 2001, 467-468, 541-544.

[46] Schmitz, D.; Rossner, H.; Imperia, P.; Maletta, H.; Bahrdt, J.; Follath, R.; Frentrup, W.; Gaupp, A.; Holldack, K.; Mertins, H. C. et al. Commissioning results of the UE46-PGM beamline. BESSY Annual Report. 2002, 358-361.

[47] Poletti, M. G.; Branz, S.; Fiore, G.; Szost, B. A.; Crichton, W. A.; Battezzati, L. Equilibrium high entropy phases in X-NbTaTiZr (X = $\mathrm{Al}, \mathrm{V}, \mathrm{Cr}$ and $\mathrm{Sn}$ ) multiprincipal component alloys. J. Alloys Compd. 2016, 655, 138-146.

[48] Timoshenko, J.; Kuzmin, A. Wavelet data analysis of EXAFS spectra. Comput. Phys. Commun. 2009, 180, 920-925.

[49] Funke, H.; Scheinost, A. C.; Chukalina, M. Wavelet analysis of extended X-ray absorption fine structure data. Phys. Rev. B 2005, 71, 094110. 
[50] La Torre, E.; Smekhova, A.; Schmitz-Antoniak, C.; Ollefs, K.; Eggert, B.; Cöster, B.; Walecki, D.; Wilhelm, F.; Rogalev, A.; Lindner, J. et al. Local probe of irradiation-induced structural changes and orbital magnetism in $\mathrm{Fe}_{60} \mathrm{Al}_{40}$ thin films via an orderdisorder phase transition. Phys. Rev. B 2018, 98, 024101.

[51] Antoniak, C. Extended X-ray absorption fine structure of bimetallic nanoparticles. Beilstein J. Nanotechnol. 2011, 2, 237-251.

[52] Kuzmin, A.; Timoshenko, J.; Kalinko, A.; Jonane, I.; Anspoks, A. Treatment of disorder effects in X-ray absorption spectra beyond the conventional approach. Radiat. Phys. Chem. 2020, 175, 108112.

[53] Nascimento, C. B.; Donatus, U.; Ríos, C. T.; Antunes, R. A. Electronic properties of the passive films formed on $\mathrm{CoCrFeNi}$ and $\mathrm{CoCrFeNiAl} \mathrm{high} \mathrm{entropy} \mathrm{alloys} \mathrm{in} \mathrm{sodium} \mathrm{chloride} \mathrm{solution.} J$. Mater. Res. Technol. 2020, 9, 13879-13892.

[54] Shi, Y. Z.; Yang, B.; Rack, P. D.; Guo, S. F.; Liaw, P. K.; Zhao, Y. High-throughput synthesis and corrosion behavior of sputterdeposited nanocrystalline $\mathrm{Al}_{x}(\mathrm{CoCrFeNi})_{100-x}$ combinatorial highentropy alloys. Mater. Des. 2020, 195, 109018.

[55] Botton, G. A.; Guo, G. Y.; Temmerman, W. M.; Humphreys, C. J. Experimental and theoretical study of the electronic structure of Fe, Co, and Ni aluminides with the B2 structure. Phys. Rev. B 1996, 54 , $1682-1691$.

[56] Anne, B. R.; Shaik, S.; Tanaka, M.; Basu, A. A crucial review on recent updates of oxidation behavior in high entropy alloys. SN Appl. Sci. 2021, 3, 366.

[57] Chaudhary, V.; Soni, V.; Gwalani, B.; Ramanujan, R. V.; Banerjee, $\mathrm{R}$. Influence of non-magnetic $\mathrm{Cu}$ on enhancing the low temperature magnetic properties and Curie temperature of $\mathrm{FeCoNiCrCu}_{x}$ high entropy alloys. Scr. Mater. 2020, 182, 99-103.

[58] Thole, B. T.; Carra, P.; Sette, F.; van der Laan, G. X-ray circular dichroism as a probe of orbital magnetization. Phys. Rev. Lett. 1992, 68, 1943-1946.
[59] Carra, P.; Thole, B. T.; Altarelli, M.; Wang, X. D. X-ray circular dichroism and local magnetic fields. Phys. Rev. Lett. 1993, 70, 694-697.

[60] Meyer, J.; Tombers, M.; van Wüllen, C.; Niedner-Schatteburg, G.; Peredkov, S.; Eberhardt, W.; Neeb, M.; Palutke, S.; Martins, M.; Wurth, W. The spin and orbital contributions to the total magnetic moments of free Fe, Co, and Ni clusters. J. Chem. Phys 2015, 143, 104302.

[61] Stöhr, J.; Siegmann, H. C. Magnetism: from Fundamentals to Nanoscale Dynamics; Springer-Verlag: Berlin, 2006.

[62] Söderlind, P.; Eriksson, O.; Johansson, B.; Albers, R. C.; Boring, A. M. Spin and orbital magnetism in Fe-Co and Co-Ni alloys. Phys. Rev. B 1992, 45, 12911-12916.

[63] Wu, R. Q.; Freeman, A. J. Limitation of the magnetic-circulardichroism spin sum rule for transition metals and importance of the magnetic dipole term. Phys. Rev. Lett. 1994, 73, 1994-1997.

[64] Langenberg, A.; Hirsch, K.; Ławicki, A.; Zamudio-Bayer, V.; Niemeyer, M.; Chmiela, P.; Langbehn, B.; Terasaki, A.; Issendorff, B. V.; Lau, J. T. Spin and orbital magnetic moments of size-selected iron, cobalt, and nickel clusters. Phys. Rev. B 2014, 90, 184420.

[65] Timoshenko, J.; Keller, K. R.; Frenkel, A. I. Determination of bimetallic architectures in nanometer-scale catalysts by combining molecular dynamics simulations with X-ray absorption spectroscopy. J. Chem.Phys. 2017, 146, 114201.

[66] Timoshenko, J.; Jeon, H. S.; Sinev, I.; Haase, F. T.; Herzog, A.; Cuenya, B. R. Linking the evolution of catalytic properties and structural changes in copper-zinc nanocatalysts using operando EXAFS and neural-networks. Chem. Sci. 2020, 11, 3727-3736.

[67] Yeh, J. W.; Chen, S. K.; Lin, S. J.; Gan, J. Y.; Chin, T. S.; Shun, T. T.; Tsau, C. H.; Chang, S. Y. Nanostructured high-entropy alloys with multiple principal elements: Novel alloy design concepts and outcomes. Adv. Eng. Mater. 2004, 6, 299-303. 